NASA TECHNICAL NOTE

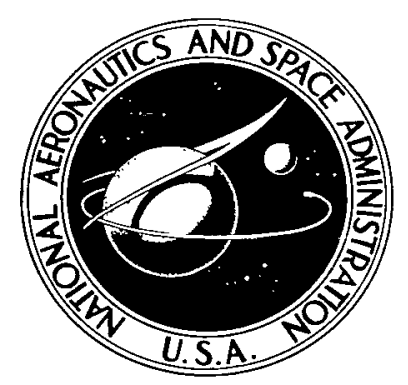

NASA TN D-8167

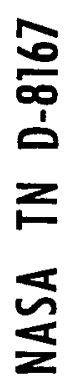

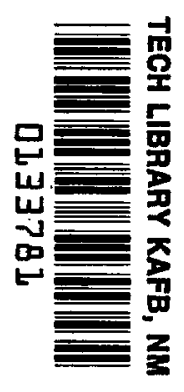

LOAN COPY: RETURN TO A FWL TECHNICAL LIBRARY KIRTLAND AFE, N. M.

\title{
ALLOY SOFTENING IN BINARY IRON SOLID SOLUTIONS
}

Joseph R. Stephens and Walter R. Witzke Lewis Research Center Cleveland, Obio 44135

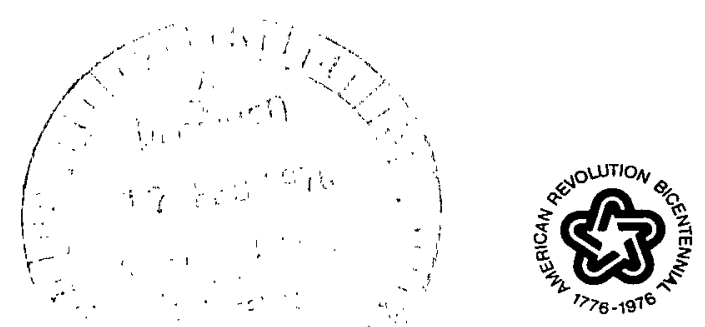

NATIONAL AERONAUTICS AND SPACE ADMINISTRATION - WASHINGTON, D. C. FEBRUARY 1976 
1. Report No. NASA TN D-8167

4. Title and Subtitle

\section{ALLOY SOFTENING IN BINARY} IRON SOLID SOLUTIONS

7. Author(s)

Joseph R. Stephens and Walter R. Witzke

9. Performing Organization Name and Address Lewis Research Center National Aeronautics and Space Administration Cleveland, Ohio 44135

12. Sponsoring Agency Name and Address

National Aeronautics and Space Administration

Washington, D. C. 20546

15. Supplementary Notes

\section{Government Accession No.}$$
\text { 3. Recipient's }
$$

5. Report Date

February 1976

6. Performing Organization Code

8. Performing Organization Report No.

E -8479

10. Work Unit No.

\section{6-16}

11. Contract or Grant No.

13. Type of Report and Period Covered

Technical Note

14. Sponsoring Agency Code

16. Abstract

An investigation was conducted to determine softening and hardening behavior in 19 binary ironalloy systems. Microhardness tests were conducted at four temperatures in the range 77 to $411 \mathrm{~K}$. Alloy softening was exhibited by 17 of the 19 alloy systems. Alloy softening observed in 15 of the alloy systems was attributed to an intrinsic mechanism, believed to be lowering of the Peierls (lattice friction) stress. Softening and hardening rates could be correlated with the atomic radius ratio of solute to iron. Sof tening observed in two other systems was attributed to an extrinsic mechanism, believed to be associated with scavenging of interstitial impurities.

17. Key Words (Suggested by Author(s))

Iron alloys

Solid solutions

Hardness
Alloy softening

Atomic size

Strengthening
18. Distribution Statement

Unclassified - unlimited

STAR Category 26 (rev.)

19. Security Classif. (of this report) Unclassified

20. Security Classif. (of this page) Unclassified
21. No. of Pages

28
22. Price*

$\$ 3.75$

\footnotetext{
* For sale by the National Technical Information Service, Springfield, Virginia 22161
} 
CONTENTS

Page

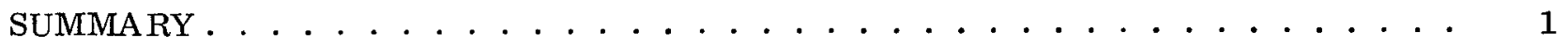

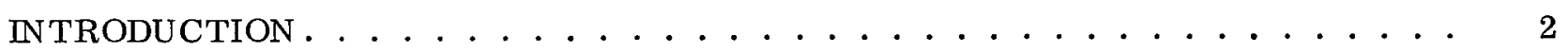

EXPERIMENTAL PROCEDURE. . . . . . . . . . . . . . . 3

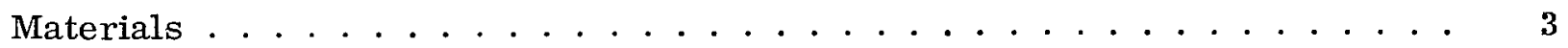

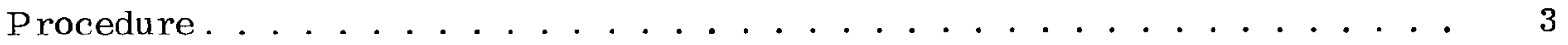

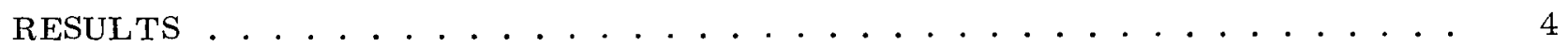

Solute Effects . . . . . . . . . . . . . . . . . 4

Temperature Effects ........................ 5

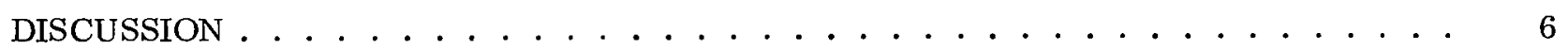

Alloy Softening and Hardening . . . . . . . . . . . . 6

Controlling Mechanisms . . . . . . . . . . . . . . . 8

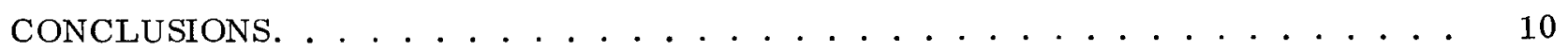

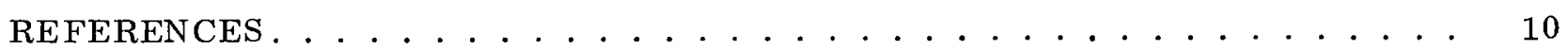





\section{INTRODUCTION}

Alloy softening in body-centered-cubic (bcc) metals is a well-established phenomenon. The extent of current interest in alloy softening in iron ( $\mathrm{Fe}$ ) as well as other bcc metals is evident from the bibliographies in the review papers by Leslie (ref. 1) and Pink (ref. 2) as well as in the more recent paper by Leemans and Fine (ref. 3). These papers conclude that alloy softening occurs at low temperatures in bcc metals as a result of either substitutional or interstitial alloy additions. As noted by Pink (ref. 2), the amount of interstitial solute required to produce maximum softening at low temperatures normally ranges from 0.02 to 0.05 at. \%. This is much lower than the 2 to 10 at. \% concentration of substitutional solutes that is usually required to produce softening under similar test conditions. These results suggest that there may be more than one mechanism controlling alloy softening for the two types of solute additions.

Our previous results for other bcc metals (refs. 4 to 7) also suggest that more than one mechanism may be operative in alloy softening, dependent upon the solvent metal. Alloy softening in Group VI solvent metals, chromium (Cr), molybdenum (Mo), and tungsten $(\mathrm{W})$, could be correlated with the electron concentration in the alloys (refs. 4 to 6). In contrast, we attributed alloy softening in a Group V solvent metal, niobium $(\mathrm{Nb})$, to scavenging of interstitial impurities (ref. 7). This is in agreement with the previously reported findings of others on softening in $\mathrm{Nb}$ and tantalum (Ta) (refs. 8 and 9). Alloy softening in Fe has been attributed to an extrinsic mechanism (i.e., scavenging of interstitial impurities), as well as to intrinsic mechanisms, such as lowering of the Peierls stress (ref. 10).

Many of the previous studies on softening in Fe alloys have involved only two or three alloy systems and have covered only a small concentration range (refs. 3 and 10 to 13). In order to reduce the effects of interstitial impurities in Fe, several investigators have added titanium (Ti) to Fe to "getter" carbon $(\mathrm{C})$, oxygen $(\mathrm{O})$, and nitrogen (N) (refs. 1 and 10). Because of the limited scope of these studies, the variation in purity of the iron alloys, and the possible complicating effects due to "gettering" of $\mathrm{Fe}$ by $\mathrm{T} i$, it is not possible to compare the results of the different investigations. The most comprehensive study on Fe alloys to date was the work of Leslie (ref. 1).

The purposes of our investigation were twofold. The primary purpose was to determine if alloy softening in Fe alloys was dependent upon electron concentration in a manner similar to that observed in Group VI metals or upon scavenging of interstitial impurities as observed in Group $V$ metals. A secondary purpose was to provide a direct comparison of alloy softening and hardening in several binary Fe-alloy systems having the same processing history.

Alloy additions to $\mathrm{Fe}$ included the elements in the portion of the Periodic Table 
shown in figure 1 (with the exception of technetium). A total of 19 alloy systems were investigated. Hardness testing was used as the primary means of evaluation since it provides an expedient method of determining the mechanical properties of a large number of alloys. Testing was conducted at four temperatures over a homologous temperature range of 0.043 to $0.227 \mathrm{~T}_{\mathrm{m}}$ (where $\mathrm{T}_{\mathrm{m}}$ is the absolute melting temperature of unalloyed $\mathrm{Fe}$ ) in order to encompass the temperature range where alloy softening is generally observed in bcc alloys.

\section{EXPERIMENTAL PROCEDURE}

\section{Materials}

Table I presents the analyzed compositions of the Fe-base alloys in atomic percent. Interstitial contents in ppm by weight are also listed in table I for several alloys from each alloy system. Starting materials for this investigation included vacuum-processed Fe and Ti; high-purity electron-beam-melted vanadium (V), Nb, Ta, Mo, W, and rhenium (Re); iodide $\mathrm{Cr}$; electrolytic manganese (Mn), nickel (Ni), and cobalt (Co); commercial-purity zirconium $(\mathrm{Zr})$ sheet, hafnium (Hf) turnings, and palladium (Pd) and platinum (Pt) foils; and hydrogen-annealed ruthenium ( $\mathrm{Ru}$ ), osmium (Os), rhodium (Rh), and iridium (Ir) powders.

Ingots were prepared by nonconsumable triple arc-melting of 70-gram charges in a water-cooled copper mold, followed by drop casting into a square-cross-section mold. Slices approximately 3 millimeters thick and 15 millimeters on a side were cut from the cast ingots for hardness testing. One face of each specimen that was to be used for hardness testing was given a metallographic polish. Specimens were normally annealed in a vacuum of $1 \times 10^{-4} \mathrm{~N} / \mathrm{m}^{2}$ or better for 1 hour at the temperature where maximum solubility occurs in the $\alpha$ region. This anneal was followed by a 16-hour anneal at $300^{\circ} \mathrm{C}$ in order to produce single-phase, homogenized, equiaxed, strain-free specimens.

\section{Procedure}

Alloying elements for binary Fe alloys were selected from the fourth, fifth, and sixth periods of the Periodic Table and included all the solute elements in Groups IV to VIII with the exception of technetium, as shown in figure 1. Also shown in figure 1 are the number of bonding electrons (ref. 14) of the elements and the atomic radius ratio of solute element to Fe (ref. 15). The selection of solute concentration in each 
alloy series was based on the Fe-solute phase diagrams (refs. 16 to 18). Solute concentrations ranged from approximately 0.5 at. \% for those elements that have extremely limited solubility in Fe to approximately 16 at. \% for those elements that form a continuous series of solid solutions with Fe.

Test temperatures were selected to cover the range where alloy softening is normally observed in Fe alloys, less than $0.11 \mathrm{~T}_{\mathrm{m}}$ (refs. 1 and 10), and also were extended to higher temperatures, where alloy hardening is usually observed. Test temperatures included $77,188,300$, and $411 \mathrm{~K}$ or $0.043,0.104,0.166$, and $0.227 \mathrm{~T}_{\mathrm{m}}$, respectively.

The modified microhardness test unit used in this study has been described previously (ref. 4). A minimum of 10 diamond pyramid hardness impressions were made on each alloy at each test temperature. A load of 1 kilogram and a dwell time of 15 seconds were used for the impressions. Hardness readings were taken only of impressions within the grains. The relative standard deviation was 5 percent.

\section{RESULTS}

\section{Solute Effects}

Description of the effects of solute additions to Fe is arranged by Groups of the Periodic Table to facilitate presentation of the data. Figure 2 shows the hardness behavior of Fe alloyed with the Group IV elements $\mathrm{Ti}, \mathrm{Zr}$, and $\mathrm{Hf}$. Alloy softening was observed at $77 \mathrm{~K}$ for $\mathrm{Ti}$ additions to about 4 at. \%. The maximum solubility of $\mathrm{Ti}$ in $\mathrm{Fe}$ is nearly 8 at.\% (ref. 16). For the Fe-8.12Ti alloy listed in table I, the hardness was 366 Vickers hardness number (VHN) at $77 \mathrm{~K}$ compared to $207 \mathrm{VHN}$ for an Fe-3.86- Ti alloy at the same test temperature. This increase in hardness suggests that the solubility limit was exceeded at the higher Ti concentration. At $188 \mathrm{~K}$, the hardness reached a minimum near 1.02 at. \% Ti and then increased sharply at higher Ti contents. Alloy softening was not observed at 300 and $411 \mathrm{~K}$ in the binary Fe-Ti alloys. Figure 2 also shows the hardness response of binary $\mathrm{Fe}-\mathrm{Zr}$ and Fe-Hf alloys. Both of these elements have extremely limited solubilities in Fe. Alloy softening was not observed in either of these two alloy systems at the four test temperatures used for this investigation.

The effects of the Group V elements V, Nb, and Ta on the hardness of Fe are shown in figure 3. Vanadium, which forms a complete series of solid solutions with Fe, exhibited a hardness minimum at approximately 2 at. \%. In contrast, hardness minimums were observed in Fe-Nb and Fe-Ta alloys near 0.1 to 0.2 at. \%. The solubilities of $\mathrm{Nb}$ and $\mathrm{Ta}$ in $\mathrm{Fe}$ are both less than 0.5 at.\%, suggesting that the high hardnesses in 
these alloy systems at 0.5 and 1.0 at. \% solute are due to the appearance of hard $\mathrm{Fe}_{2} \mathrm{Nb}$ and $\mathrm{Fe}_{2} \mathrm{Ta}$ phases, respectively.

The effects of the Groups VI, VII, and VIII solute elements on the hardness of Fe are shown in figures 4 to 8 . In most cases, hardness minimums occur between 1 and 4 at. \% solute at $77 \mathrm{~K}$ in these 13 alloy systems. At $188 \mathrm{~K}$ the hardness minimums shift to lower solute concentrations, near 1 at. \% in most instances. At the higher temperatures, 300 and $411 \mathrm{~K}$, softening usually was not observed. On a homologous temperature basis for the Fe alloys, $300 \mathrm{~K}$ corresponds to $0.166 \mathrm{~T}_{\mathrm{m}}$. Previous results on several binary Mo alloys (ref. 5) as well as $\mathrm{Cr}-\mathrm{Re}$ and $\mathrm{W}-\mathrm{Re}$ alloys (ref. 4) have shown that alloy softening does not occur above homologous temperatures of about 0.165. The decrease of solute content at the hardness minimum with increase in temperature and the final disappearance of alloy softening near $0.166 \mathrm{~T}$ in Fe alloys are in agreement with prior results for the Group VI metals $\mathrm{Cr}$, Mo, and W.

One notable exception to the general hardness behavior exhibited by the binary FeGroups VI, VII, and VIII alloys was that of Fe-Cr alloys. As shown in figure 4, a hardness minimum occurs near 8 at. $\% \mathrm{Cr}$ at $77 \mathrm{~K}$ and near 4 at. \% $\mathrm{Cr}$ at $188 \mathrm{~K}$, much higher solute contents than observed in the other binary Fe-alloy systems. There was also a small decrease in hardness of 3 to $5 \mathrm{VHN}$, at 300 and $411 \mathrm{~K}$ in the $\mathrm{Fe}-1$ at.\% $\mathrm{Cr}$ alloy.

The effects of the 19 solute additions on the hardness of Fe at $77 \mathrm{~K}$, where alloy softening predominates, are summarized schematically in figure 9. The results can be characterized by three types of behavior. Fourteen of the solute additions produce initial softening in Fe followed by gradual hardening at solute concentrations past the hardness minimum, which occurs at 1 to 4 at.\% solute. The hardness behavior in the Fe-Cr alloy system is similar except that softening extends to a much higher solute content. Alloys containing $\mathrm{Nb}$ and $\mathrm{Ta}$ additions, however, exhibited slight softening near 0.1 at.\% solute followed by rapid hardening. In contrast with these two types of behavior, alloy softening did not occur in binary Fe- $\mathrm{Zr}$ and Fe-Hf alloy systems.

\section{Temperature Effects}

The dependence of hardness on temperature is shown in figures 10 to 16 , where the data are again presented by Periodic Groups. Data for unalloyed Fe are also shown along with those for each of the binary alloys for comparative purposes.

Figure 10(a) presents the data for Fe and Fe-Ti alloys. For unalloyed Fe below $300 \mathrm{~K}$, hardness increases rapidly with decreasing temperature. However, above $300 \mathrm{~K}$, hardness is independent of temperature. This type of behavior in Fe has been described previously by Conrad (ref. 19), where $300 \mathrm{~K}$ was identified as the approximate temperature at which the thermal component of the yield stress goes to zero. Our 
results show that for unalloyed Fe the temperature dependence of hardness is in agreement with the temperature dependence of yield stress. Additions of $\mathrm{Ti}$ to Fe reduce the temperature dependence of its hardness at the lower test temperatures (fig. 10(a)). In contrast, Fe-Zr (fig. 10(b)) and Fe-Hf (fig. 10(c)) alloys exhibit a temperature dependence of hardness quite similar to that for unalloyed Fe. Alloy softening did not occur in these two alloy systems.

Additions of the Group $\mathrm{V}$ metals to Fe caused similar behavior, as shown in figure 11. Dilute additions of $\mathrm{V}$ to Fe reduced the temperature dependence of its hardness over the 77 to $300 \mathrm{~K}$ temperature range (fig. 11(a)). Although additions of 0.10 at. \% $\mathrm{Nb}$ and 0.17 at. \% Ta lowered the hardness of Fe, as in alloy softening, the temperature dependence of hardness was unchanged compared to unalloyed Fe. This occurred because at these dilute levels of $\mathrm{Nb}$ and $\mathrm{Ta}$, softening occurred over the entire temperature range, as shown in figures 11 (b) and (c). Niobium and Ta additions of nearly 0.5 and 1.0 at.\% in Fe produced hardening over the entire temperature range, and the temperature dependence of hardness of these alloys paralleled that for unalloyed Fe.

The effects of adding alloys from Groups VI, VII, and VIII are shown in figures 12 to 16 and are quite similar. All 13 elements shown in these figures reduced the temperature dependence of $\mathrm{Fe}$ at the lower test temperatures.

The temperature dependence of $\mathrm{Fe}$ and the 19 binary $\mathrm{Fe}$ alloys at dilute solute concentrations is summarized schematically in figure 17. Fifteen of the solute additions produced the type of alloy softening that has been observed in other bcc alloys. This behavior is characterized by a reduction in the temperature dependence of hardness, as shown in figure 17. Two solute additions, $\mathrm{Nb}$ and $\mathrm{Ta}$, also produced softening, but the softening occurred at all four test temperatures so that the temperature dependence of hardness remained comparable to that for unalloyed Fe. Additions of $\mathrm{Zr}$ and Hf did not produce alloy softening in $\mathrm{Fe}$, and the temperature dependence of hardness for binary $\mathrm{Fe}$ alloys containing these additions was quite similar to that for unalloyed $\mathrm{Fe}$.

\section{DISCUSSION}

\section{Alloy Softening and Hardening}

Leslie, in his review of dilute solid solutions of Fe (ref. 1), noted that alloy softening has been observed in 21 different Fe-alloy systems. As a result of our investigation, we can add five more elements $(\mathrm{Nb}, \mathrm{Ta}, \mathrm{W}$, Os, and $\mathrm{Pd}$ ) that also produce alloy softening in Fe. We also confirmed that 12 of the elements identified by Leslie (Ti, V, $\mathrm{Cr}, \mathrm{Mo}, \mathrm{Mn}, \mathrm{Re}, \mathrm{Ru}, \mathrm{Co}, \mathrm{Rh}, \mathrm{Ir}, \mathrm{Ni}$, and $\mathrm{Pt}$ ) produce softening in $\mathrm{Fe}$. In addition, we identified $\mathrm{Zr}$ and $\mathrm{Hf}$ as two elements that do not produce alloy softening in Fe. 
One of the primary purposes of this investigation was to determine if electron concentration was important in controlling hardness of binary Fe alloys. Analysis of our data failed to reveal any correlation of alloy softening or alloy hardening with the number of $s+d$ electrons contributed by the solute elements (fig. 1). This was not too surprising, since the effect of solute content on the hardness of 14 of the binary $\mathrm{Fe}$ alloys was similar (fig. 9), regardless of the Pexiodic Table Group represented by the solute element.

The schematic representations of the data shown in figures 9 and 17 suggest that the 19 alloy systems studied can be divided into three separate categories. The basis for this separation is the atomic radius ratio of solute to $F e$ (fig. 1). Atomic radius ratio was used rather than the more conventional lattice parameter change with solute concentration since the latter is not available for many of the alloy systems. The radius ratios of solute to $\mathrm{Fe}$ are shown in figure 18 for the elements studied herein. The horizontal dashed lines in the figure represent the \pm 15 percent size difference limit for favorable solid-solution formation as suggested by Hume-Rothery (ref. 14).

The first category to be considered includes $\mathrm{Zr}$ and $\mathrm{Hf}$, those elements that did not produce alloy softening in $\mathrm{Fe}$ and did not change the temperature dependence of hardness. Examination of figure 18 shows that these two elements lie well beyond the +15 percent limit for solid-solution formation.

The second category to be considered includes those elements that produced softening at very dilute concentrations followed by rapid hardening, but that did not change the temperature dependence of hardness. Elements in this category include $\mathrm{Nb}$ and $\mathrm{Ta}$, which are noted in figure 18 to lie just out of the +15 percent size limit for solidsolution formation. Although $\mathrm{Ti}$ has an atomic radius ratio approaching those for $\mathrm{Nb}$ and $\mathrm{Ta}$, its hardness behavior did not resemble the behavior noted for this category. The difference in behavior of these three elements is matched by a large difference in solubility. While $\mathrm{Nb}$ and $\mathrm{Ta}$ have a solubility limit of less than 1 at.\%, the maximum solubility of $\mathrm{Ti}$ in $\mathrm{Fe}$ is nearly 8 at.\%.

The remaining category, which comprises 15 of the elements investigated, is characterized by alloy softening at $77 \mathrm{~K}$ over solute concentrations to 8 at.\% and a reduction in the temperature dependence of hardness. Figure 18 reveals that all 15 elements lie within the \pm 15 percent limit for solid-solution formation.

Based on these correlations, it appears that atomic size plays a dominant role in controlling hardness in binary Fe alloys. Previous results on Nb-base alloys (ref. 7) have shown that hardening rates could be correlated with atomic size misfit (difference between radii of solute and $\mathrm{Fe}$ divided by radius of $\mathrm{Fe}$ ). Figure 19 presents a correlation of alloy softening rates for the 15 binary Fe-alloy systems with solute-to-iron atomic radius ratios within the \pm 15 percent size limit. Because alloy softening is most prominent at lower temperatures, softening rates at the lowest test temperature, $77 \mathrm{~K}$, 
were used for the correlation. For those elements in figure 19 that have smaller atomic radii than $\mathrm{Fe}$ (i.e., $\mathrm{Co}, \mathrm{Ni}$, and $\mathrm{Mn}$ ), a separate correlation exists between softening rates and atomic radius ratios as compared to those elements that have larger atomic radii than $\mathrm{Fe}$. For the 12 elements having larger atomic radii than Fe, good agreement between softening rates and radius ratios exists, with the exception of $\mathrm{W}$ and Ti. The correlations shown in figure 19 indicate that atomic size is an important parameter in controlling alloy softening in binary Fe-base alloys.

A similar correlation of hardening rates with atomic radius ratio is presented in figure 20. Because alloy softening is minimal or nonexistent at higher test temperatures, hardening rates at $411 \mathrm{~K}$, the highest test temperature in this investigation, were used for the correlations in figure 20 . Those elements with smaller atomic radii than $\mathrm{Fe}$ again fit a different relation with radius ratio than those elements with larger atomic radii than $\mathrm{Fe}$. With the exception of $\mathrm{Pd}$, agreement of hardening rates with atomic radius ratios is excellent for 14 of the alloy systems investigated, thus suggesting that atomic size is the primary factor in controlling alloy hardening in Fe. Leslie (ref. 1) concluded that size misfit parameter is a reasonably good indicator of the strengthening of $\alpha-\mathrm{Fe}$ by low concentrations of substitutional solutes. In the work by Spitzig and Leslie (ref. 10) on $\mathrm{Fe}-3$ at.\% Co, Ni, or Si alloys, it was suggested that alloy softening at lower temperatures should be most marked in alloys that show pronounced alloy hardening near $295 \mathrm{~K}$. Based on our results of alloy softening at $77 \mathrm{~K}$ and alloy hardening at $411 \mathrm{~K}$, this hypothesis is confirmed. For example, Mn exhibits a high hardening rate at $411 \mathrm{~K}$ and a high softening rate at $77 \mathrm{~K}$, while for co both the hardening rate at $411 \mathrm{~K}$ and the softening rate at $77 \mathrm{~K}$ are relatively small. Our results further confirm that both alloy softening and alloy hardening are controlled by the solute-to-Fe atomic radius ratio or the atomic misfit in 15 of the alloy systems that were investigated. A similar analysis of the data in terms of shear modulus (as reported previously by Leslie (ref. 1)) failed to show a correlation between the softening or hardening rates and the change in shear modulus produced by the solute elements.

\section{Controlling Mechanisms}

Alloy softening in Fe has been alternately attributed to lowering of the Peierls or lattice friction stress, to promotion of cross slip, and to scavenging of interstitial impurities. The first two mechanisms are intrinsic effects, while the third mechanism is an extrinsic effect. Based on a study of three alloys, $\mathrm{Fe}-3$ at.\% $\mathrm{Co}$, $\mathrm{Ni}$, or $\mathrm{Si}$, and examination of literature data, Spitzig and Leslie (ref. 10) concluded that the controlling mechanism for alloy softening in Fe alloys was a decrease in the lattice friction stress as a result of solute atoms nucleating kinks on screw dislocations, an intrinsic effect. 
The other mechanisms proposed did not fit their experimental data. Based on the results of our study of 19 binary Fe alloys with similar impurity levels, we conclude that alloy softening is an intrinsic effect in most cases. Alloy softening observed for 15 alloy systems (whose atomic radii were within the \pm 15 percent size limit for solidsolution formation) was characteristic of an intrinsic effect and similar to alloy softening observed in the Group VI bcc metals $\mathrm{Cr}$, Mo, and W (refs. 4 to 6). These characteristics include the following:

(1) Alloy softening is more marked at lower temperatures and disappears at higher temperatures.

(2) The temperature dependence of hardness is lowered by those elements that produce alloy softening.

(3) Alloy softening at the lowest test temperature reaches a minimum in hardness at a relatively high solute concentration from 1 to 4 at.\% solute in most cases and as high as 8 at.\% for $\mathrm{Cr}$ at $77 \mathrm{~K}$.

Based on the similarity of the effects of atomic size in our results and those observed by Spitzig and Leslie (ref. 10), we conclude that the probable mechanism of alloy softening in these 15 alloy systems is lowering of the lattice friction stress.

The exception to this mechanism is the alloy softening observed with very dilute additions, nearly 0.1 at.\%, of $\mathrm{Nb}$ and Ta. Alloy softening in these two Fe-alloy systems did not meet any of the characteristics noted for intrinsic alloy softening. Softening occurred over the entire temperature range, the temperature dependence of hardness was not lowered in these alloys but paralleled unalloyed $\mathrm{Fe}$, and softening occurred at only very low solute concentrations. Based on these results, we suggest that alloy softening in $\mathrm{Fe}-\mathrm{Nb}$ and $\mathrm{Fe}-\mathrm{Ta}$ alloys arises as a result of the solute atoms scavenging interstitial impurities, an extrinsic mechanism. The results suggest that very dilute additions of $\mathrm{Nb}$ or $\mathrm{Ta}$ may be better getter additions to $\mathrm{Fe}$ than $\mathrm{Ti}$ since, at dilute concentrations of $\mathrm{Nb}$ and $\mathrm{Ta}$, hardness is not complicated by hardening at the higher test temperatures

The theories proposed to describe alloy hardening in metals normally involve a size misfit parameter and a shear modulus parameter (refs. 1 and 20). The good agreement of hardening rates with atomic size in 15 of our alloy systems suggests that atomic size may be the primary factor of importance. Shear modulus difference may be of only minor importance in these binary Fe alloys since hardening rates could not be correlated with change in shear modulus. The rapid rise in hardness observed in $\mathrm{Fe}$ alloys containing $\mathrm{Nb}, \mathrm{Ta}, \mathrm{Zr}$, and $\mathrm{Hf}$ may arise from formation of intermetallic compounds rather than because of the high atomic radius ratios. 


\section{CONCLUSIONS}

Based on a study of the hardness behavior of 19 binary iron-alloy systems, the following conclusions are drawn:

1. Atomic radius ratio of solute to iron plays a dominant role in controlling the hardness behavior of binary iron alloys.

2 . Alloy softening rates at $77 \mathrm{~K}$ and alloy hardening rates at $411 \mathrm{~K}$ can be correlated with the atomic radius ratio of solute to iron for 15 of the binary iron-alloy systems. These 15 solutes lie within the \pm 15 percent size limit suggested by HumeRothery for favorable solid-solution formation and include Ti, V, Cr, Mo, W, Mn, Re, $\mathrm{Ru}$, Os, Co, Rh, Ir, Ni, Pd, and Pt.

3. Alloy softening in these 15 alloy systems is due to an intrinsic mechanism. Similarities between our results and previous literature results suggest that lowering of the Peierls stress by solute atoms aiding kink formation on screw dislocations may be the controlling mechanism. Also, alloy hardening in these 15 alloy systems is due primarily to an intrinsic mechanism, atomic size misfit, rather than to shear modolus difference.

4. Alloy softening occurs in binary $\mathrm{Fe}-\mathrm{Nb}$ and $\mathrm{Fe}-\mathrm{Ta}$ alloy systems as a result of an extrinsic mechanism, believed to be scavenging of interstitial impurities.

5. Alloy softening does not occur in binary Fe-Zr and Fe-Hf systems because of the very large solute-to-iron atomic radius ratios.

Lewis Research Center,

National Aeronautics and Space Administration,

Cleveland, Ohio, November 17, 1975, 506-16.

\section{REFERENCES}

1. Leslie, W. C.: Iron and Its Dilute Substitutional Solid Solutions. Metal. Trans., vol. 3, no. 1, Jan 1972 , pp. 5-26.

2. Pink, Erwin: Legierungsentfestigung in Kubischraumzentrierten Metallen. Zeit. für Metal., vol. 64, no. 12, Dec. 1973, pp. 871-881.

3. Leemans, D.; and Fine, M. E.: Solid Solution Softening and Strain-Rate Sensitivity of Fe-Re and Fe-Mo Alloys. Metall. Trans., vol. 5, no. 6, June 1974, pp. 1331-1336. 
4. Stephens, J. R.; and Witzke, W. R.: Alloy Softening in Group VIA Metals Alloyed with Rhenium. J. Less-Common Metals, vol. 23, 1971, pp. 325-342.

5. Stephens, Joseph R.; and Witzke, Walter R.: Alloy Hardening and Softening in Binary Molybdenum Alloys as Related to Electron Concentration. J. LessCommon Metals, vol. 29, 1972, pp. 371-388.

6. Stephens, J. R.; and Witzke, W. R.: The Role of Electron Concentration in Softening and Hardening of Ternary Molybdenum Alloys. J. Less-Common Metals, vol. 41 , 1975, pp. 265-282.

7. Stephens, J. R.; and Witzke, W. R.: Hardness Behavior of Binary and Ternary Niobium Alloys at 77 and $300 \mathrm{~K}$. J. Less-Common Metals, vol. 40, 1975, pp. 195-205.

8. Ravi, K. V.; and Gibala, R.: The Strength of Niobium-Oxygen Solid Solutions. Acta. Met., vol. 18, no. 6, June 1970, pp. 623-634.

9. Sagues, A. A.; and Gibala, R.: Substitutional-Interstitial Solute Interactions in Ta-Re-N Solid Solutions. Scripta Met., vol. 5, no. 8, Aug. 1971, pp. 689-693.

10. Spitzig, W. A.; and Leslie, W. C.: Solid-Solution Softening and Thermally Activated Flow in Alloys of Fe with 3 At. \% Co, Ni or Si. Acta Met., vol. 19, no. 11, Nov. 1971, pp. 1143-1152.

11. Hilderbrandt, U.; and Dickenscheid, W.: Plasticity and Alloy-Softening in IronNickel-Alloys. Acta Met., vol. 19, no. 1, Jan 1971, pp. 49-55.

12. Kranzlein, H. H.; Burton, M. S.; and Smith, G. V.: Solid Solution Strengthening in Iron-Nickel and Iron-Platinum Alloys. Trans. AIME, vol. 233, no. 1, Jan. 1965, pp. 64-70.

13. Stoloff, N. S.; Davies, R. G.; and Ku, R. C.: Low-Temperature Yielding and Fracture in Fe-Co and Fe-V Alloys. Trans. AIME, vol. 233, no. 8, Aug. 1965, pp. 1500-1508.

14. Hume-Rothery, William; and Raynor, G. V.: The Structures of Metals and Alloys. Institute of Metals (London), 1956.

15. Teatum, E. T.; Gschneider, K. A., Jr.; and Waber, J. T.: Compilation of Calculated Data Useful in Predicting Metallurgical Behavior of the Elements in Binary Alloy Systems. LA-4003, Los Alamos Scientific Lab., 1968.

16. Hansen, Max; and Anderko, Kurt: Constitution of Binary Alloys. 2nd ed., McGraw-Hill Book Co., Inc., 1958. 
17. Elliott, Rodney P.: Constitution of Binary Alloys. 1st suppl., McGraw-Hill Book Co., Inc., 1965.

18. Shunk, Francis A.: Constitution of Binary Alloys. 2nd suppl., McGraw-Hill Book Co., Inc., 1969.

19. Conrad, H.: The Cryogenic Properties of Metals. High-Strength Materials, Victor F. Zackay, ed., John Wiley \& Sons, Inc., 1964, pp. 436-509.

20. Fleischer, R. L.: Substitutional Solution Hardening. Acta Met., vol. 11, no. 3, Mar. 1963, pp. 203-209. 
TABLE I. - CHEMICAL ANALYSIS AND SUMMARY OF HA RUNESS DATA FOR BINARY IRON ALLOYS

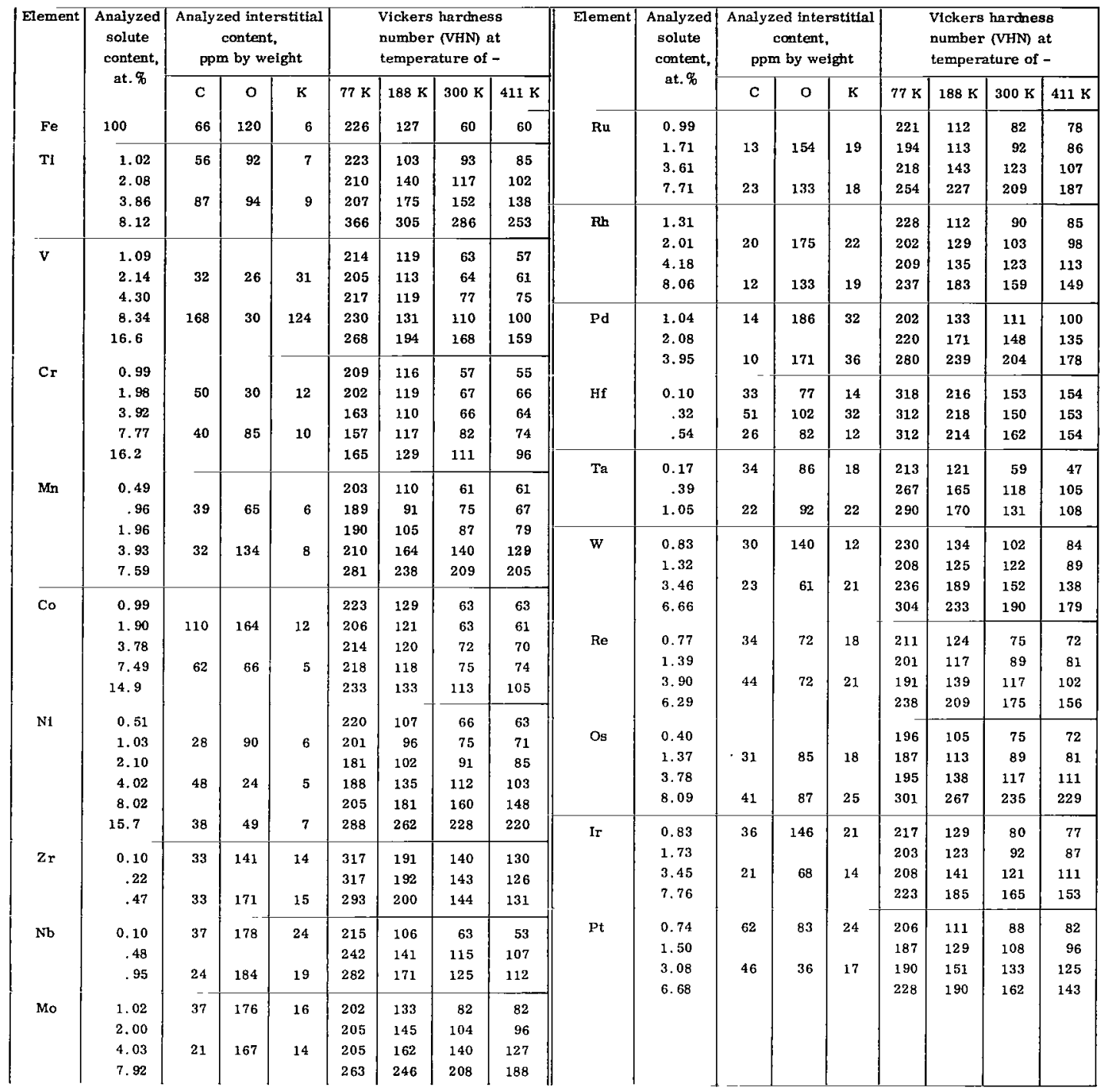

\begin{tabular}{|c|c|c|c|c|c|c|c|c|c|}
\hline \multirow{2}{*}{ Period } & \multicolumn{7}{|c|}{ Group } & \multirow{2}{*}{\multicolumn{2}{|c|}{ Reading key }} \\
\hline & IV & v & VI & VII & & VIII & & & \\
\hline Fourth & $\int_{1.1476}^{22} \mathrm{~d}^{2} s^{2}$ & $v^{23} v^{d^{3} s^{2}}$ & $\begin{array}{c}24 \underset{\mathrm{d}^{5} \mathrm{~s}^{1}}{\mathrm{Cr}} \\
1.0063\end{array}$ & $\int_{M n}^{25} \mathrm{dn}^{5} \mathrm{~s}^{2}$ & $\begin{array}{c}26 \\
\mathrm{Fe} \\
1.0000 \\
\mathrm{~d}^{62} \mathrm{~s}^{2} \\
\end{array}$ & $\begin{array}{c}27 \quad d^{7} s^{2} \\
C 0 \\
0.9827\end{array}$ & $\begin{array}{cc}28 & \mathrm{~d}^{8} \mathrm{~s}^{2} \\
\mathrm{Ni} & \\
0.9780\end{array}$ & $\begin{array}{l}\text { Atomic } \\
\text { number } \\
\end{array}$ & $\left\{\begin{array}{l}\text { Bonding } \\
\text { electrons } \\
\text { - Element }\end{array}\right.$ \\
\hline Fifth & $\begin{array}{c}40 \mathrm{~d}^{2} \mathrm{~s}^{2} \\
\mathrm{Zr} \\
\mathrm{L} \cdot \mathrm{2575} \\
\end{array}$ & $\begin{array}{ll}41 & d^{4} s^{l} \\
N b \\
1.1523\end{array}$ & $\mid \begin{array}{c}42 \\
\text { Mo } \\
1.0989 \\
s^{5} 1 \\
\end{array}$ & \begin{tabular}{|c|c}
$43 \mathrm{~d}^{6} \mathrm{~s}$ \\
$\mathrm{Tc}$ \\
1.0714 \\
\end{tabular} & $\begin{array}{cc}44 & d^{7} s^{1} \\
R u \\
R .0637 \\
\end{array}$ & \begin{tabular}{|c|}
$45 \mathrm{~d}^{8} \mathrm{~s}^{1}$ \\
$\mathrm{Rh}$ \\
1.0557 \\
\end{tabular} & $\begin{array}{|cc|}46 & d^{10} \\
& P d \\
\text { l. } 0801 \\
\end{array}$ & $\begin{array}{l}1.0000 \\
1.0\end{array}$ & $\begin{array}{l}\text { - Radius } \\
\text { ratio }\end{array}$ \\
\hline Sixth & $\int_{1.2402}^{72 \mathrm{~d}^{2} \mathrm{~s}^{2}}$ & $\begin{array}{c}73 \mathrm{~d}^{3} \mathrm{~s}^{2} \\
\mathrm{Ta} \\
1.1515\end{array}$ & $\left|\begin{array}{cc}74 & d^{4} s^{2} \\
W \\
1.1052\end{array}\right|$ & $\begin{array}{c}75 \mathrm{~d}^{5} \mathrm{~s}^{2} \\
\mathrm{Re} \\
1.0793\end{array}$ & $\left|\begin{array}{cc}76 & d^{6} s^{2} \\
0 s \\
1.0798\end{array}\right|$ & \begin{tabular}{|c|c|}
$77 \mathrm{~d}^{7} \mathrm{~s}^{2}$ \\
Ir \\
1,0651 \\
\end{tabular} & $\begin{array}{|cc|}78 & \mathrm{~d}^{8} \mathrm{~s}^{2} \\
& \mathrm{Pt} \\
1.0887 & \\
1 & 087 \\
\end{array}$ & & \\
\hline
\end{tabular}

Figure L - Partial Periodic Table showing solute elements alloyed with iron for this investigation. 


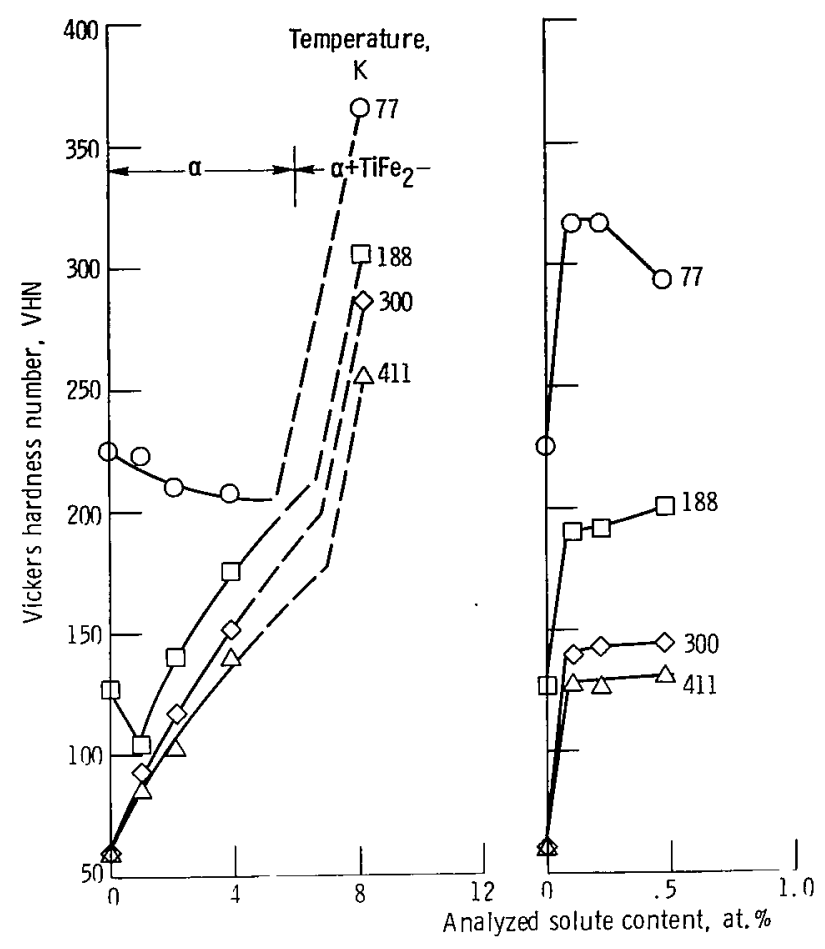

(a) Titanium.

(b) Zirconium.

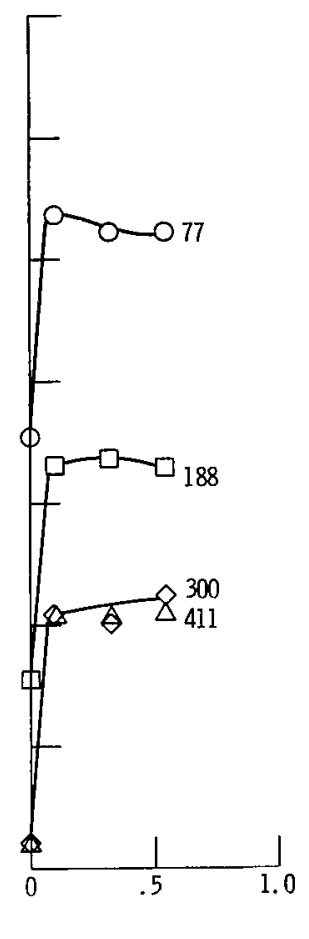

(c) Hafnium.

Figure 2. - Effect of Group IV elements $\mathrm{Ti}, \mathrm{Zr}$, and Hf on hardness of binary iron alloys.

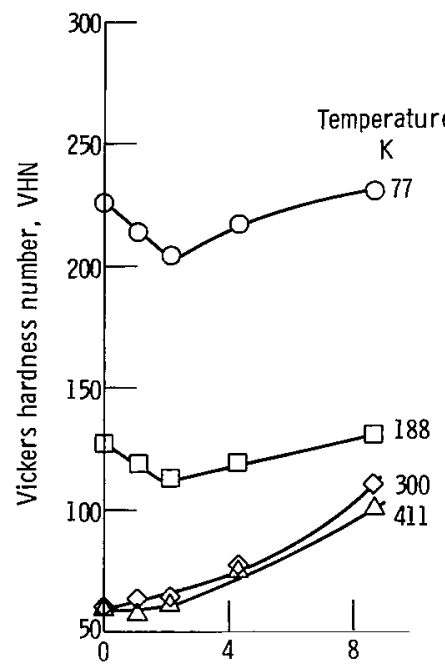

(a) Vanadium.

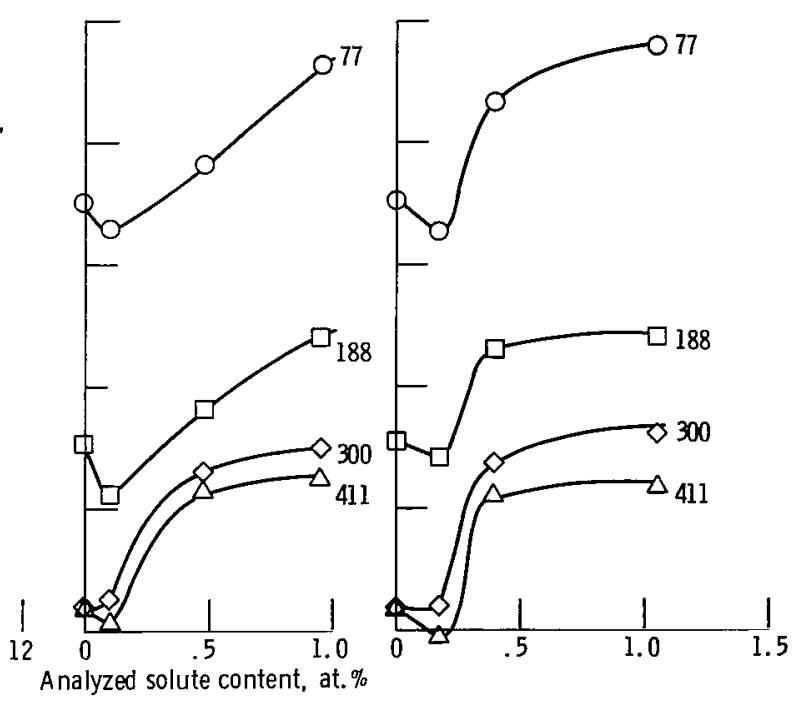

(b) Niobium.

(c) Tantalum.

Figure 3. - Effect of Group $\mathrm{V}$ elements $\mathrm{V}$, Nb, and Ta on hardness of binary iron alloys. 


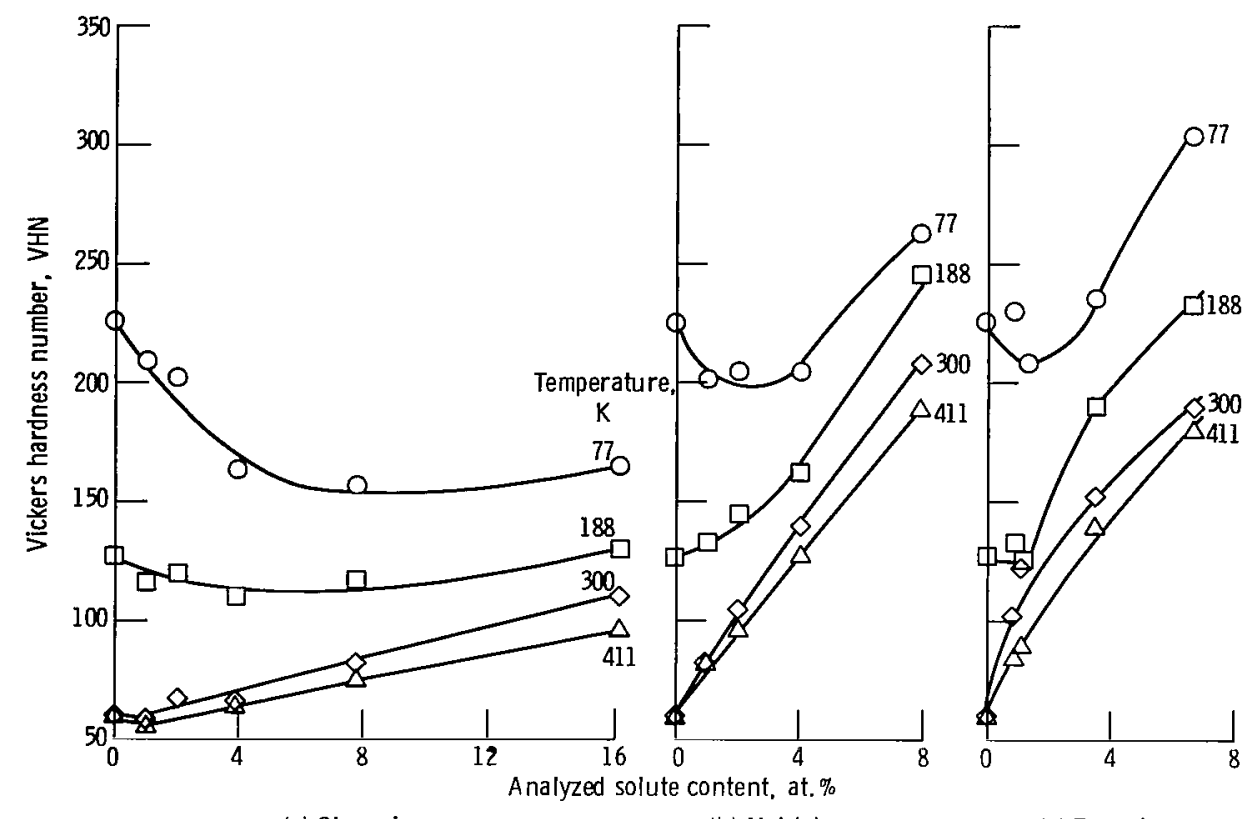

(a) Chromium.

(b) Molybdenum.

(c) Tungsten.

Figure 4. - Effect of Group VI elements $\mathrm{Cr}$. Mo, and W on hardness of binary iron alloys.

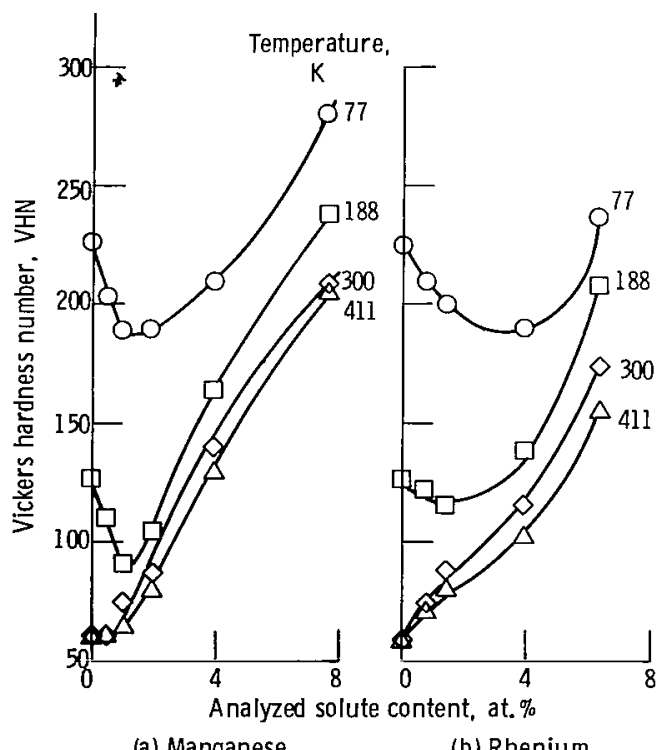

(a) Manganese.

(b) Rhenium.

Figure 5. - Effects of Group VII elements $\mathrm{Mn}$ and Re on hardness of binary iron alloys. 


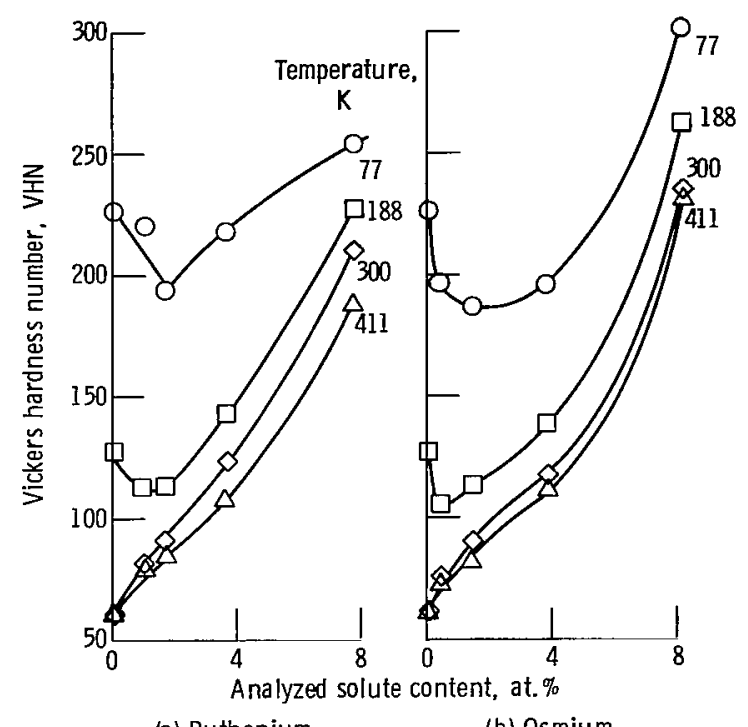

(a) Ruthenium.

(b) Osmium.

Figure 6. - Effects of Group VIII elements Ru and Os on hardness of binary iron alloys.

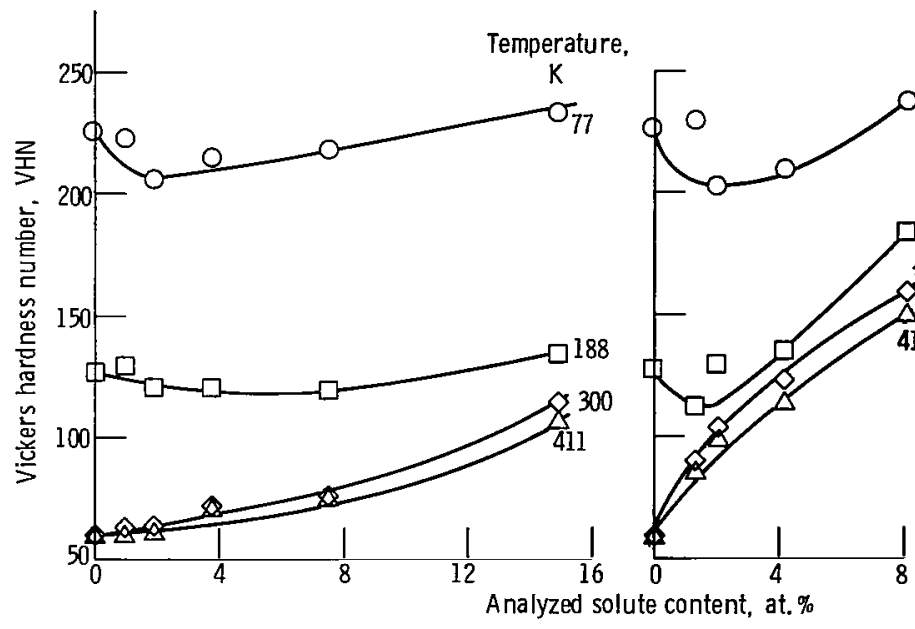

(a) Cobalt.

(b) Rhodium.

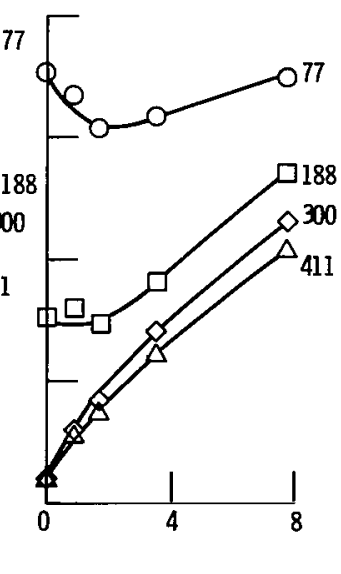

(c) Iridium.

Figure 7. - Effects of Group VIII elements $\mathrm{C}$, Rh, and Ir on hardness of binary iron alloys. 


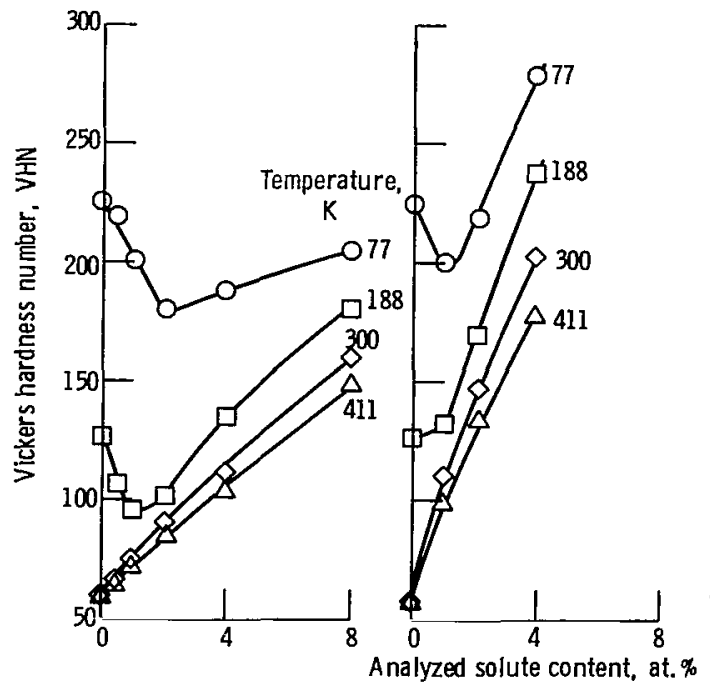

(a) Nickel.

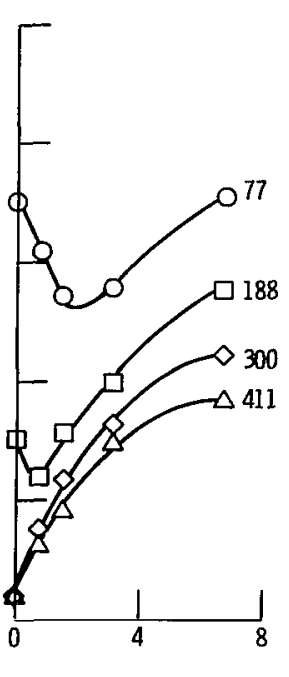

(c) Platinum.

Figure 8. - Effects of Group VIII elements Ni, Pd, and Pt on hardness of binary iron alloys.

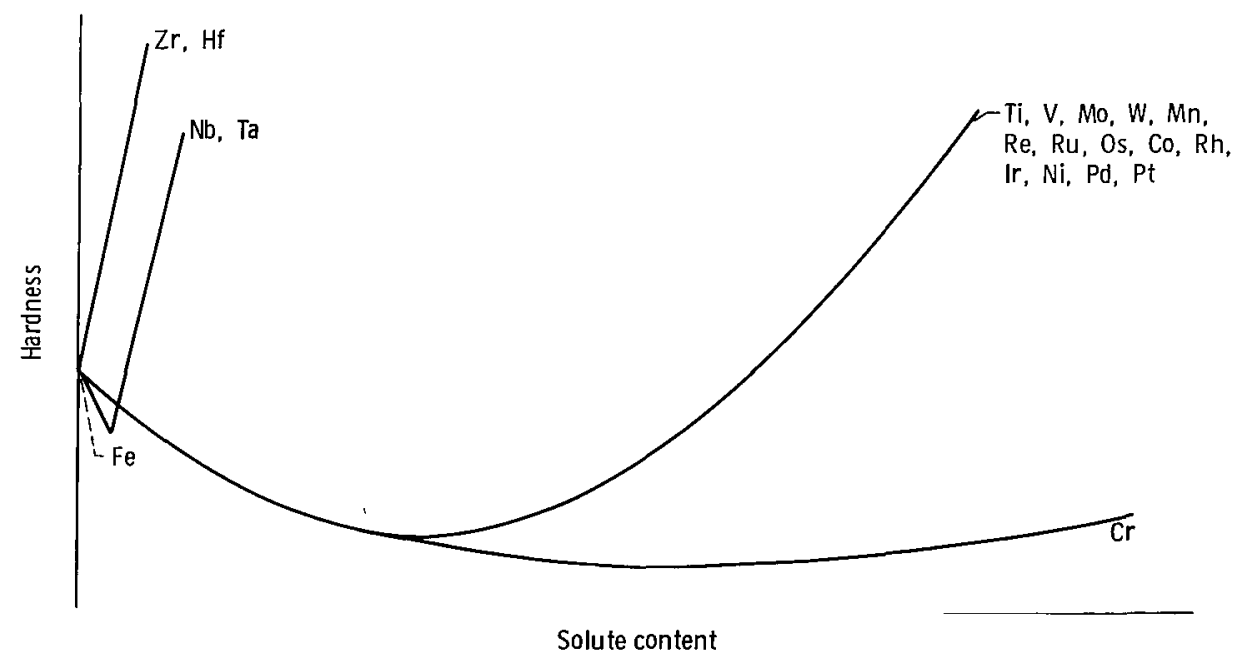

Figure 9. - Schematic representation of solute effects in binary iron alloys at $77 \mathrm{~K}$. 

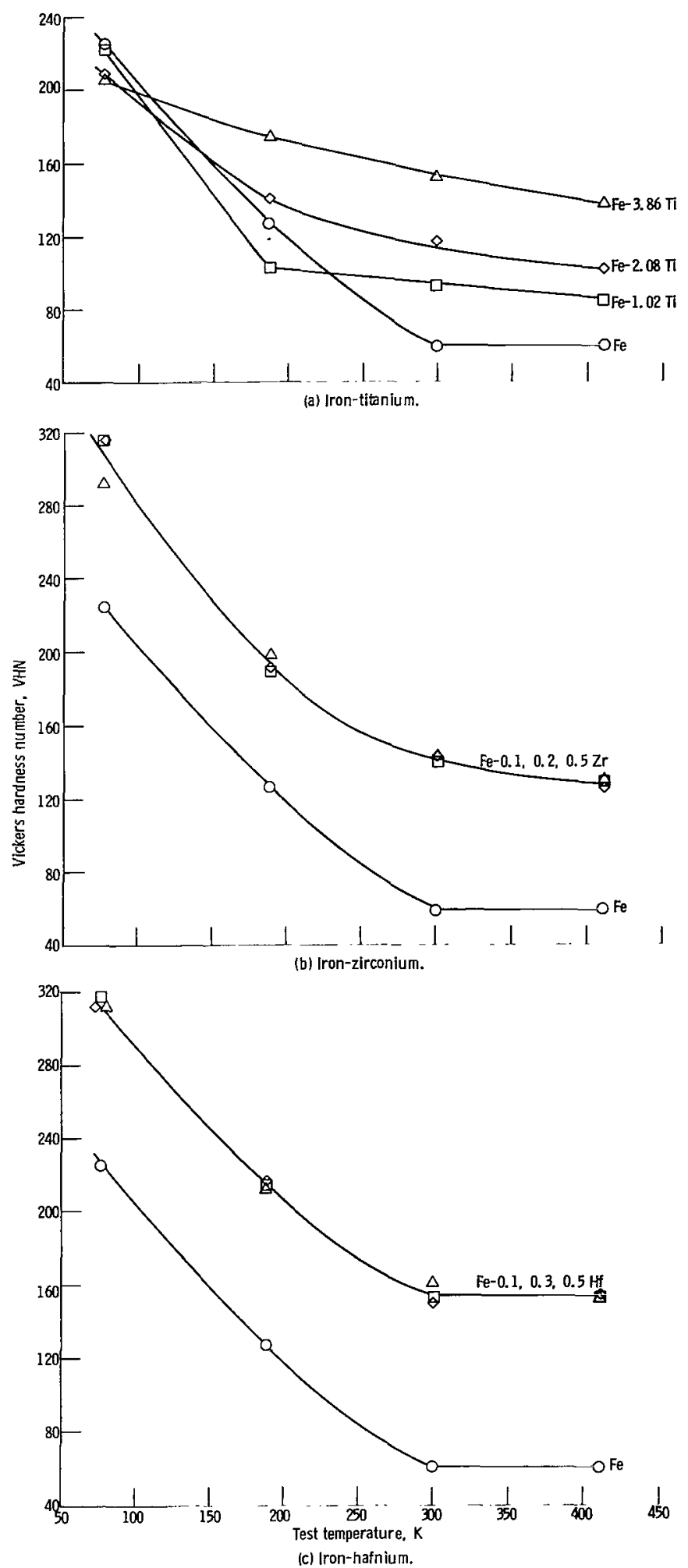

Figure 10. - Effect of test temperature on hardness of binary alloys of iron and Group IV elements $\mathrm{Ti}, \mathrm{Zr}$, and $\mathrm{HF}$. 

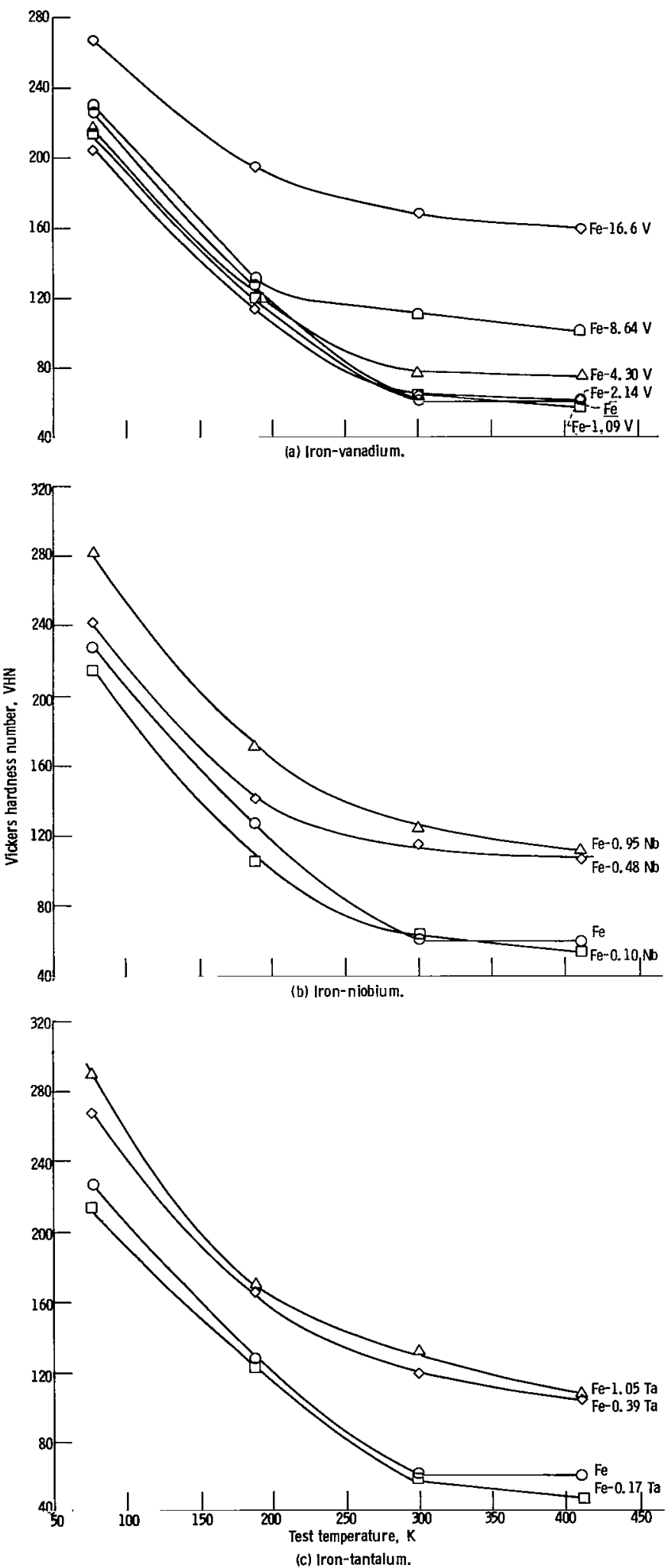

Figure 11. - Effect of test temperature on hardness of binary ailoys of iron and Group $V$ elements $\mathrm{V}, \mathrm{N}$, and $\mathrm{Ta}$. 

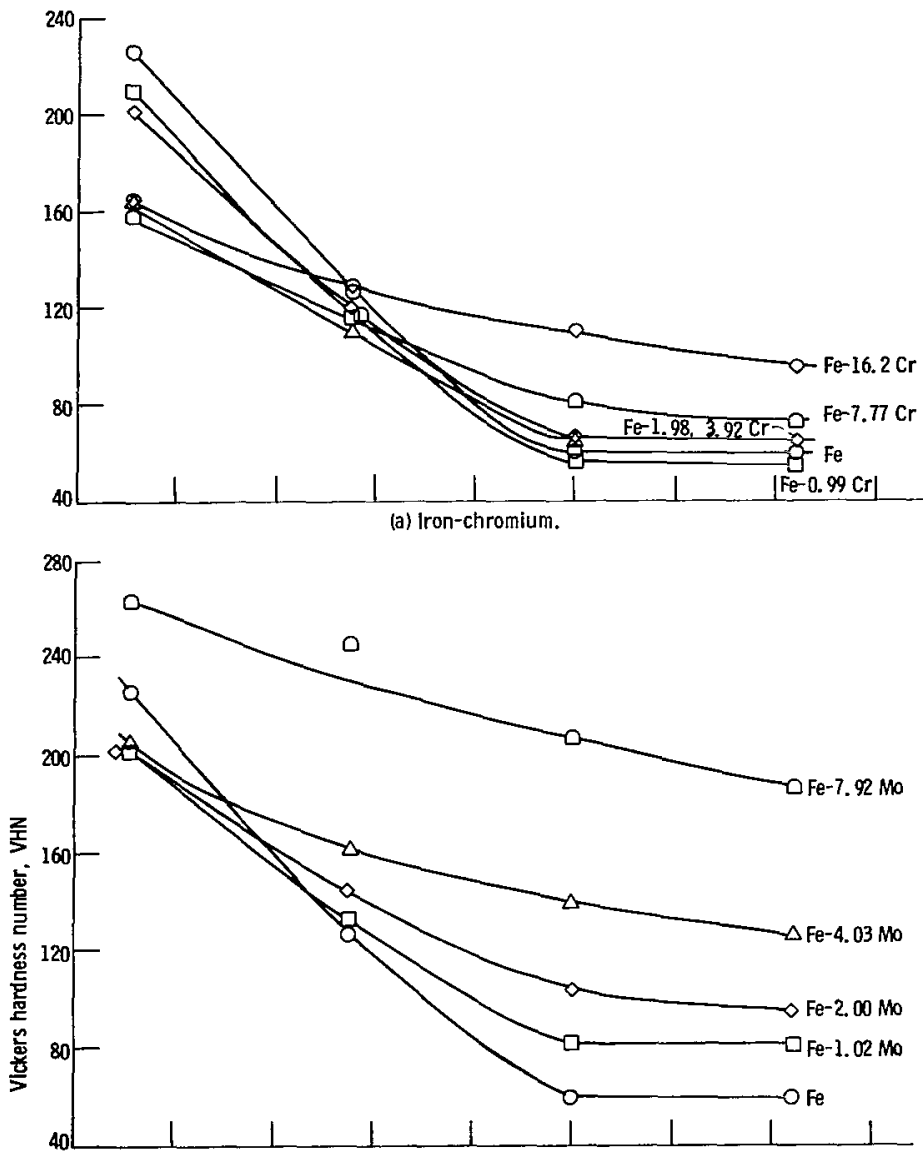

(b) Iron-molybdenum.

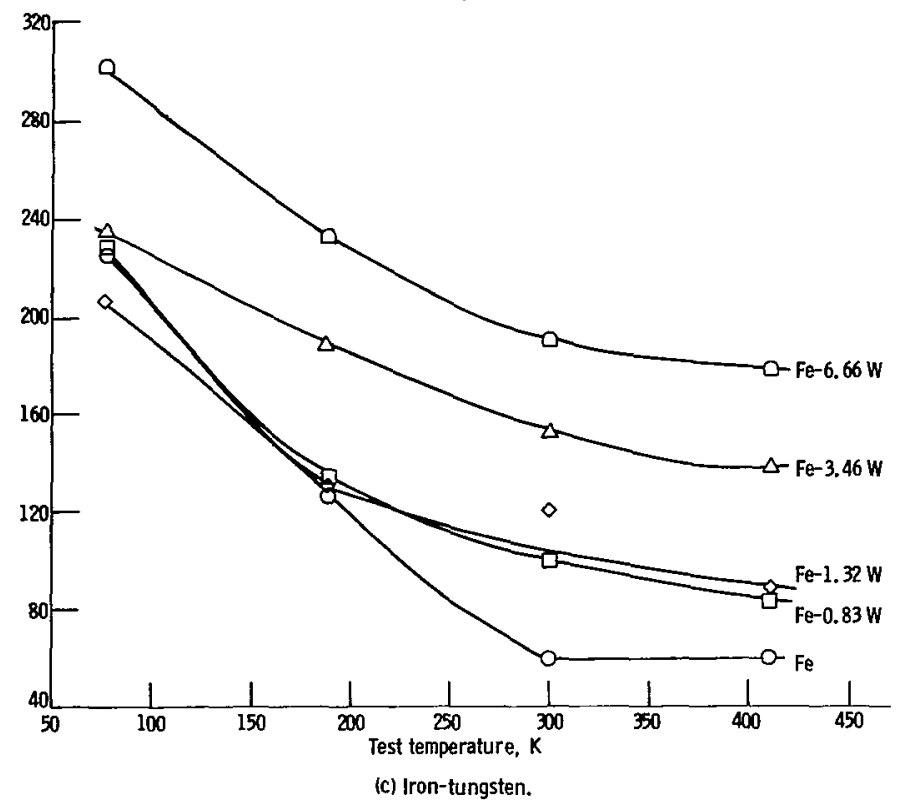

Figure 12. - Effect of test temperature on hardness of binary alloys of iron and Group VI elements $\mathrm{Cr}$, Mo, and $\mathrm{W}$. 


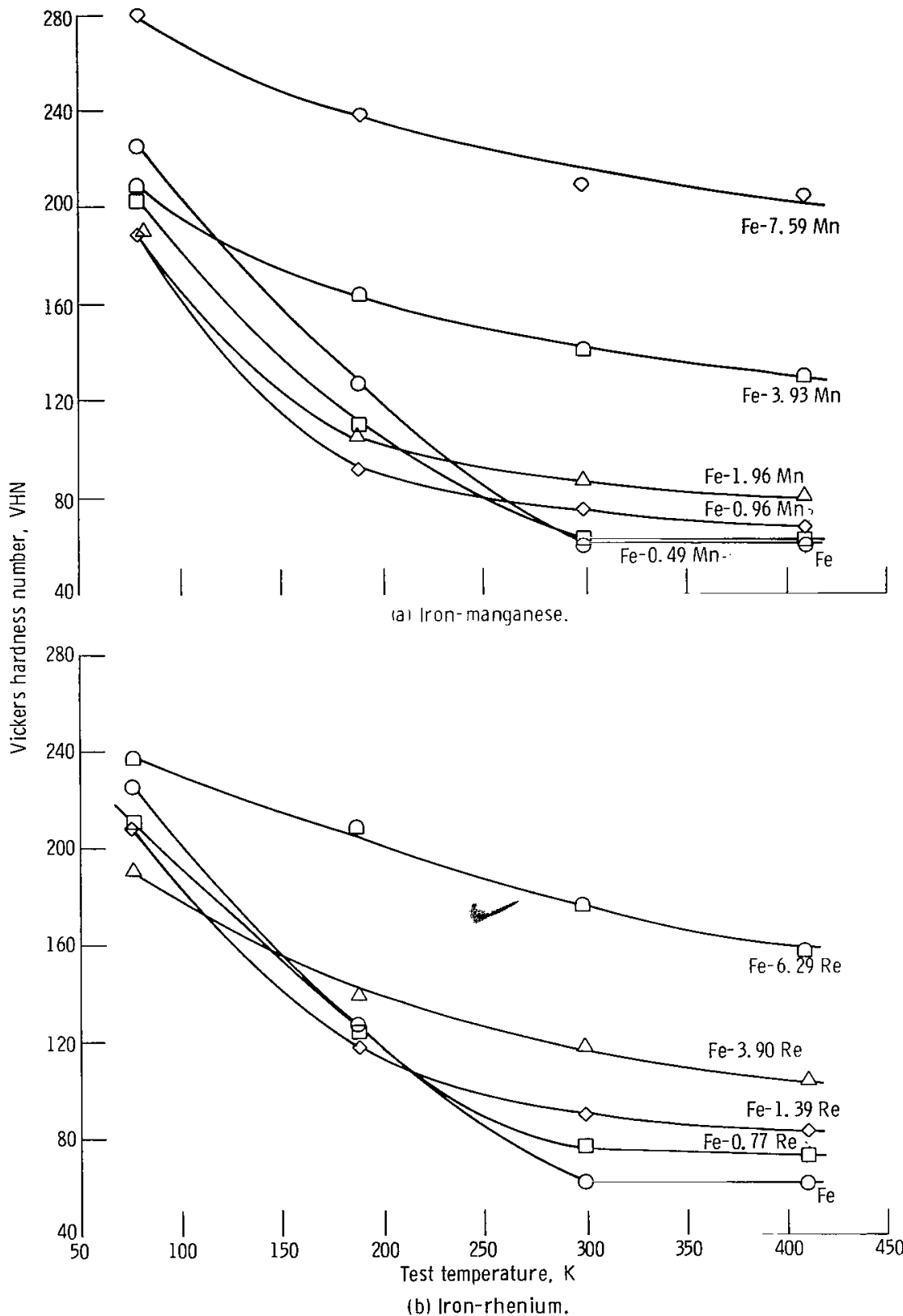

Figure 13. - Effect of test temperature on hardness of binary alloys of iron and Group VII elements $\mathrm{Mn}$ and $\mathrm{Re}$. 


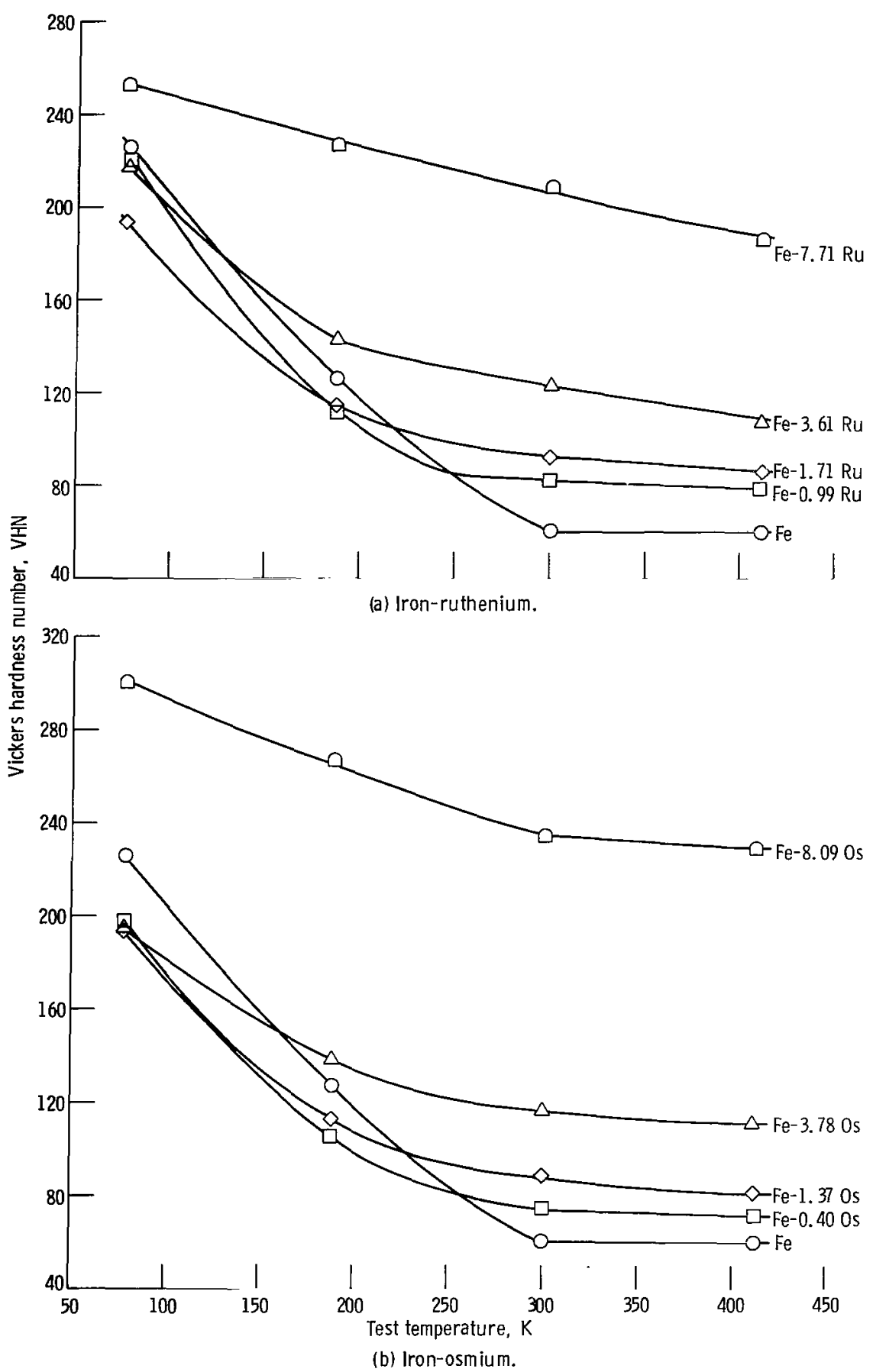

Figure 14. - Effect of test temperature on hardness of binary alloys of iron and Group VIII elements $\mathrm{Ru}$ and 0 s. 


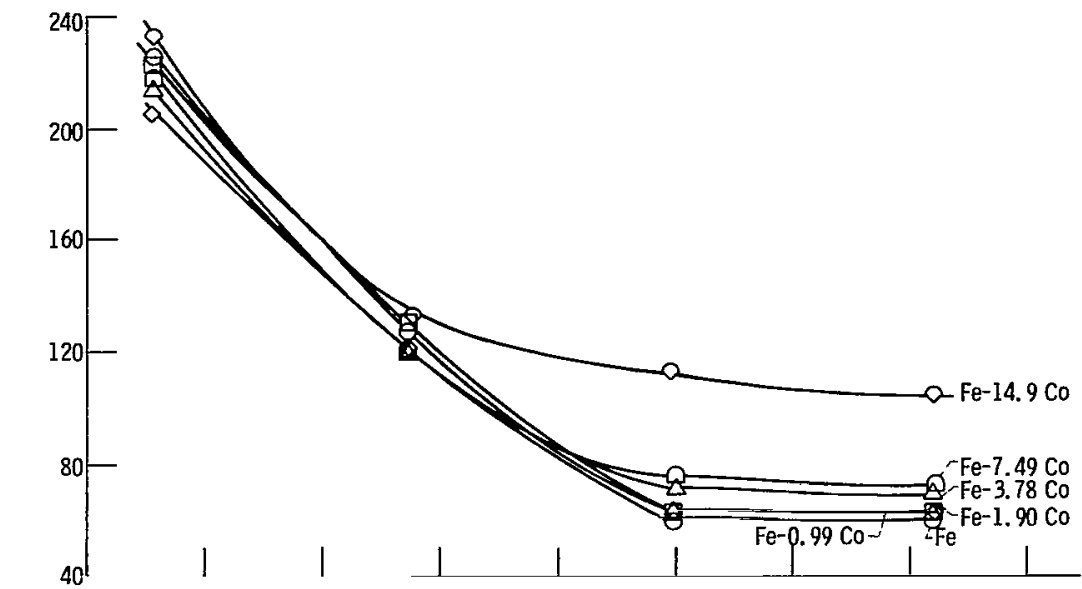

(a) Iron-cobalt.

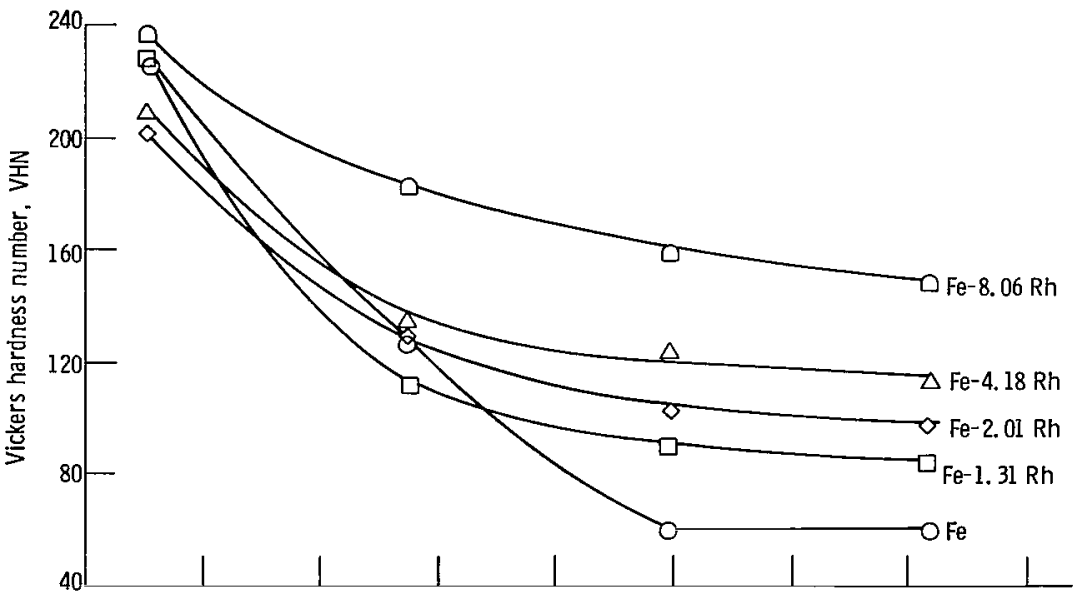

(b) Iron-rhodium.

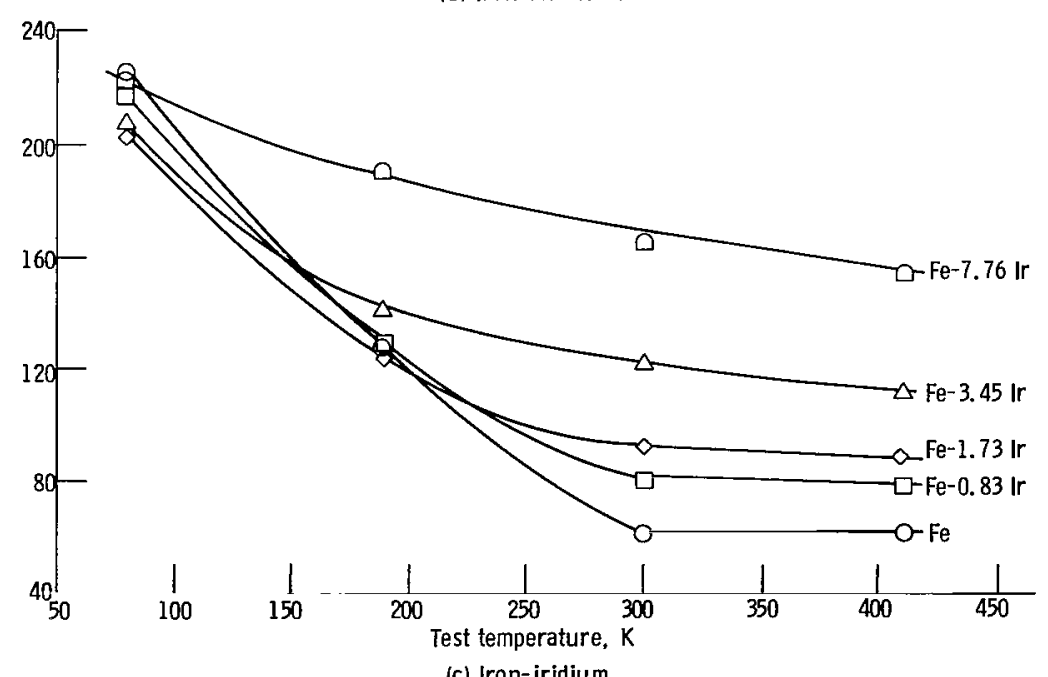

(c) Iron-iridium.

Figure 15. - Effect of test temperature on hardness of binary alloys of iron and Group VIII elements $\mathrm{Co}_{0}, \mathrm{Rh}$, and $\mathrm{Ir}$. 


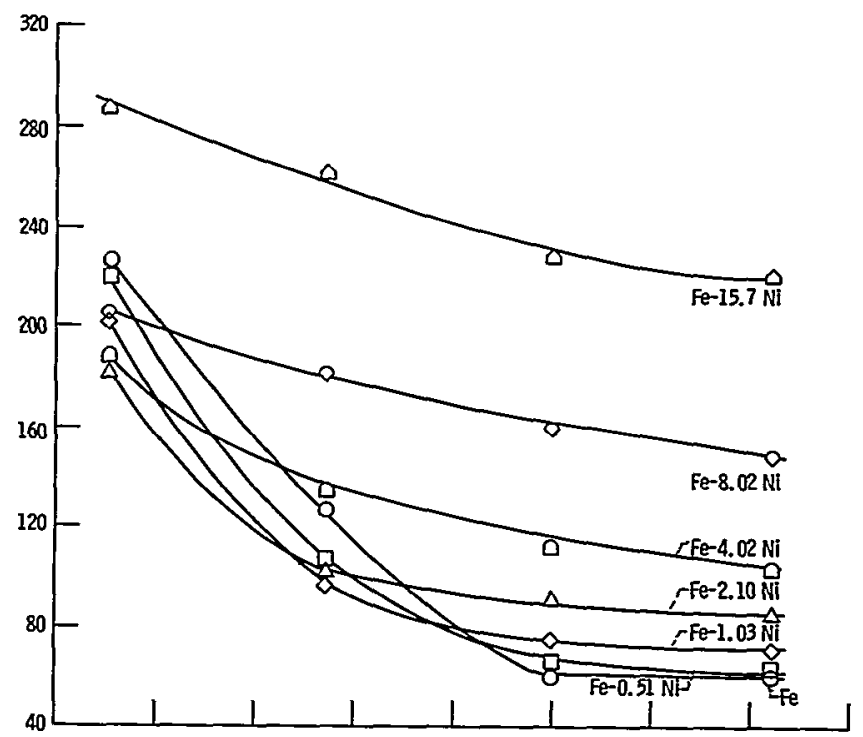

(a) Iron-nickel.
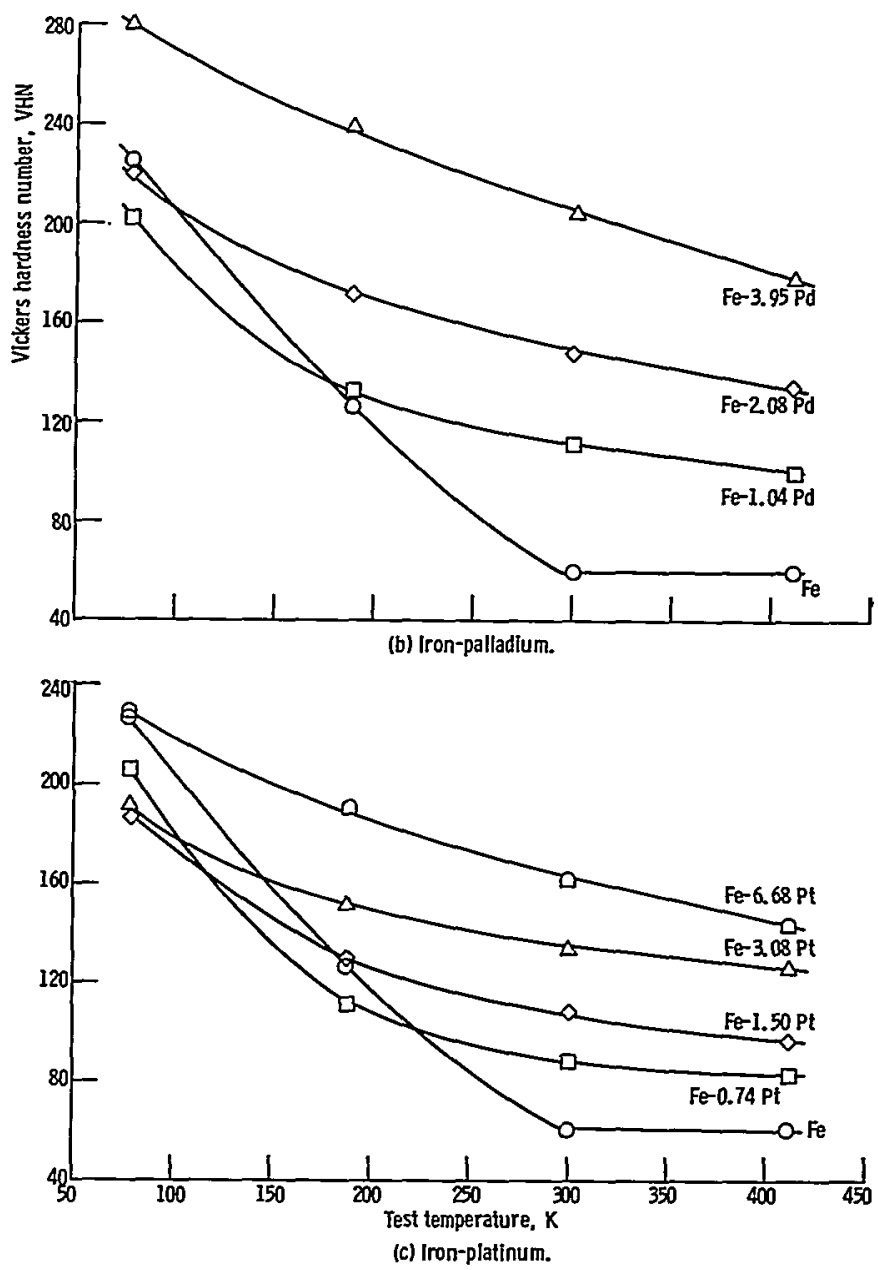

Figure 16. - Effect of test temperature on hardness of binary alloys of Iron and Group VIII elements $\mathrm{NI}, \mathrm{Pd}$, and $\mathrm{Pt}$. 


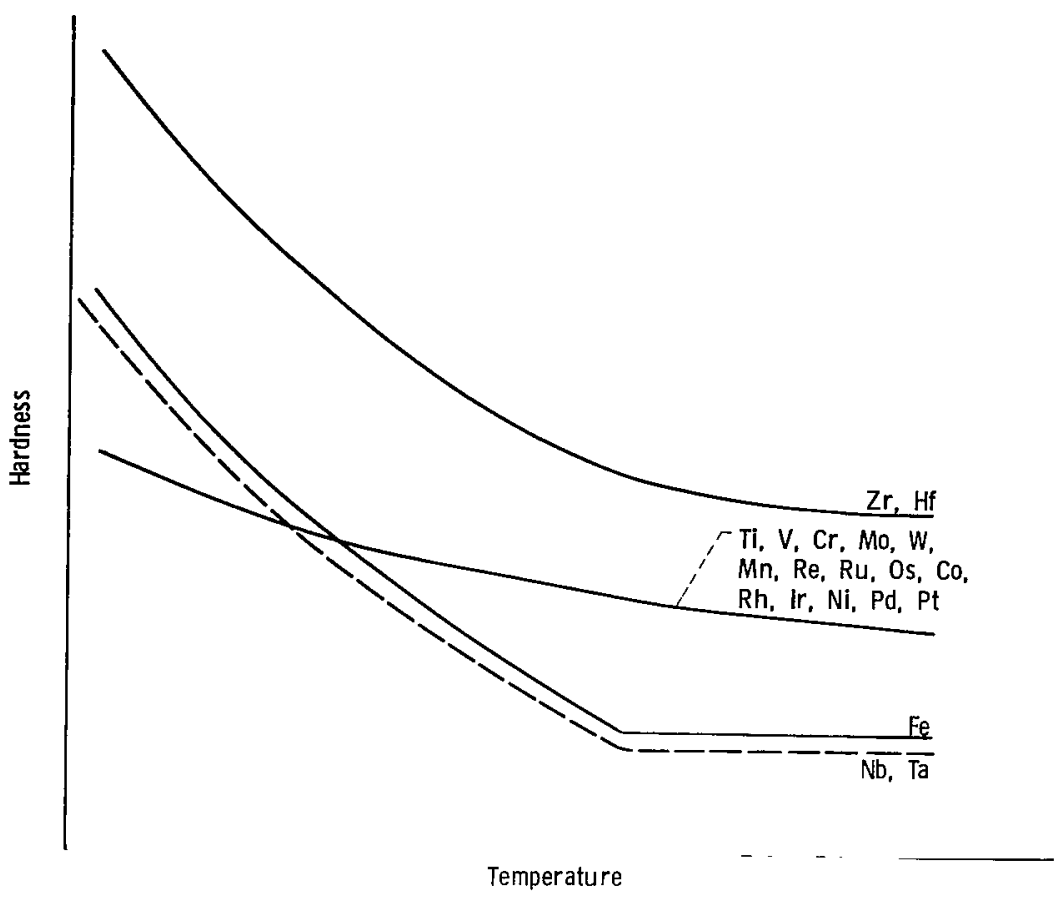

Figure 17. - Schematic representation of the temperature dependence of hardness of unalloyed iron and binary iron alloys.

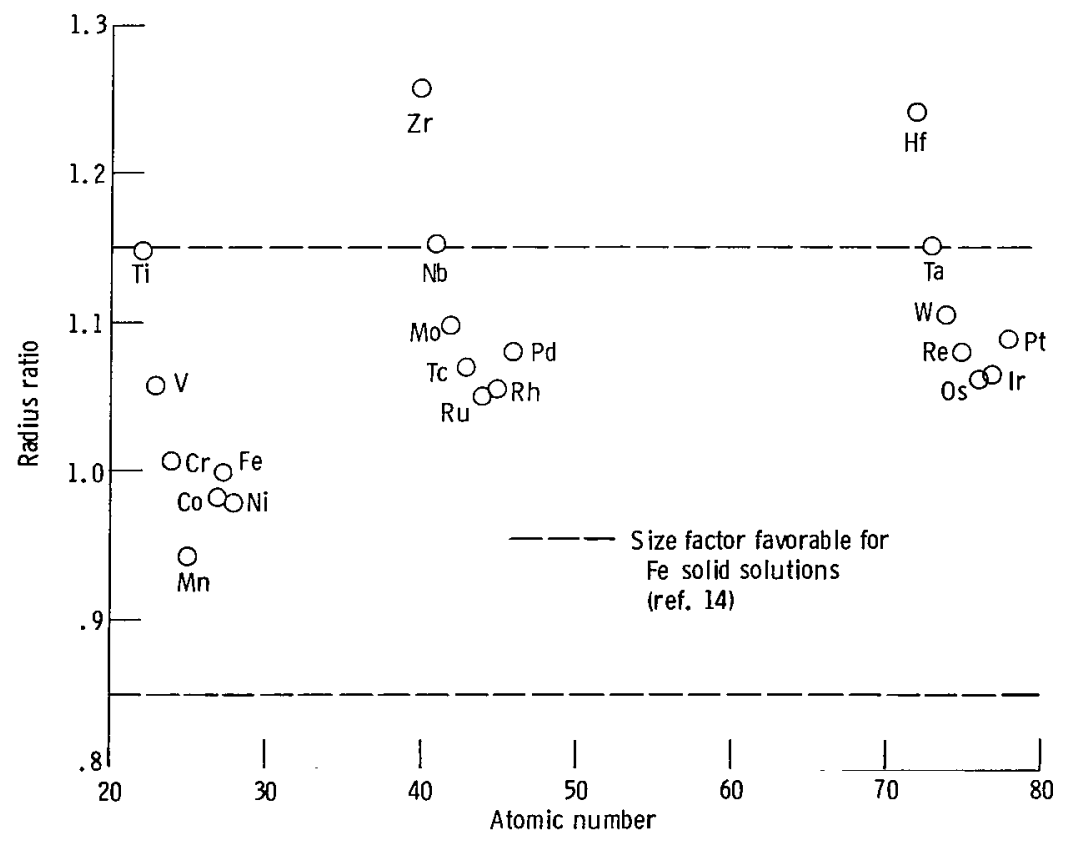

Figure 18. - Atomic radius ratio of 19 solute elements to iron and range for solidsolution formation based on a radius ratio not to exceed \pm 0.15 . 
నั
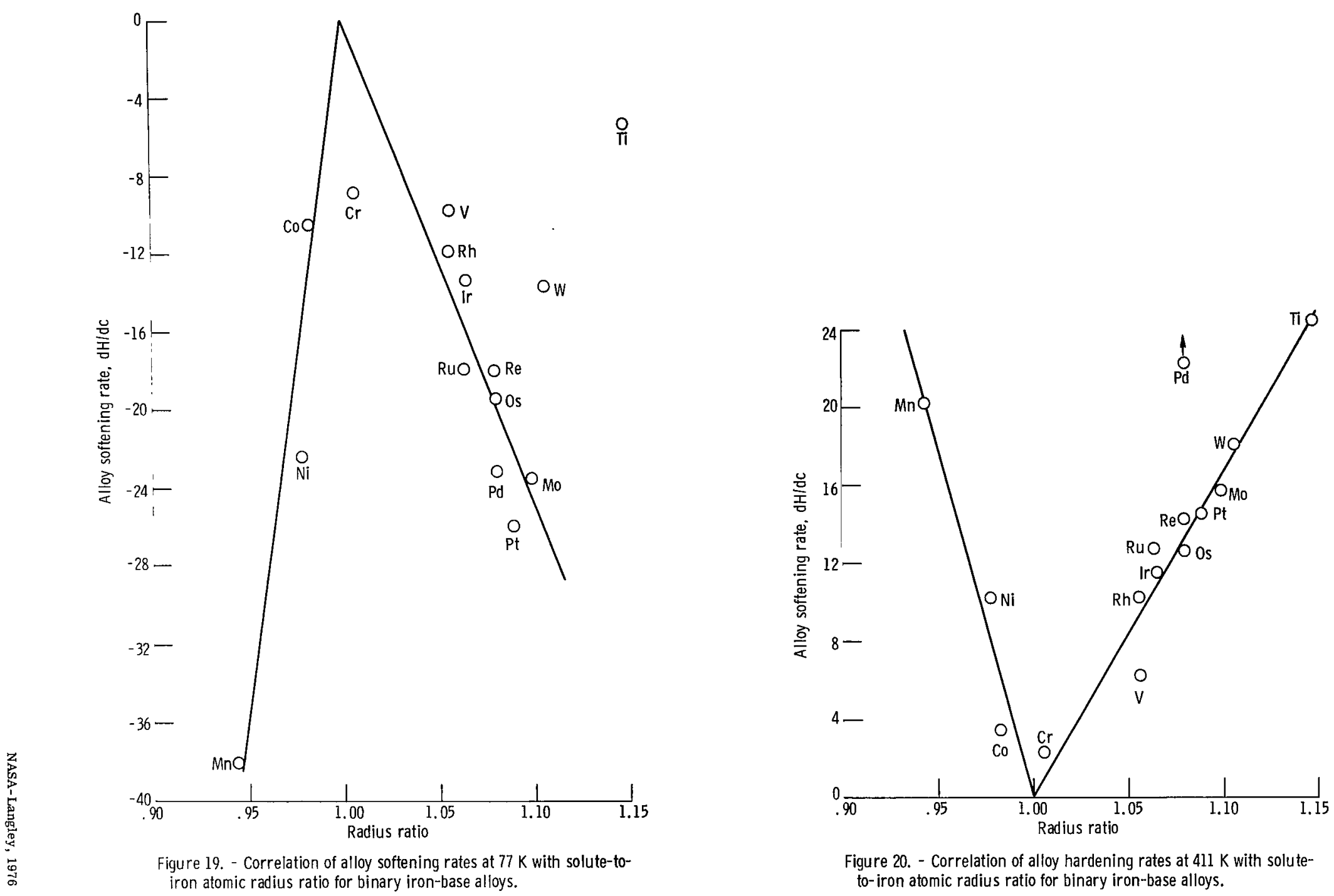

Figure 20. - Correlation of alloy hardening rates at $411 \mathrm{~K}$ with soluteto-iron atomic radius ratio for binary iron-base alloys. 


\author{
245001 C 1 U $C 760123$ S00903DS \\ DEPT OF THE AIR FORCE \\ AF WEAPONS LABORATORY \\ ATTN: TECHNICAL LIBRARY (SUL) \\ KIRTLAND AFB NM 87117
}

POSTMASTER :

"The aeronautical and space activities of the United States shall be conducted so as to contribute . . to the expansion of buman knowledge of phenomena in the atmosphere and space. The Administration shall provide for the widest practicable and appropriate dissemination of information concerning its activities and the results thereof."

-National Aeronautics and Space ACt of 1958

\title{
NASA SCIENTIFIC AND TECHNICAL PUBLICATIONS
}

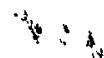

, in:
TECHNICAL REPORTS: Scientific and technical information considered important, complete, and a lasting contribution to existing knowledge.

TECHNICAL NOTES: Information less broad in scope but nevertheless of importance as a contribution to existing knowledge.

TECHNICAL MEMORANDUMS:

Information receiving limited distribution because of preliminary data, security classification, or other reasons. Also includes conference proceedings with either limited or unlimited distribution.

CONTRACTOR REPORTS: Scientific and technical information generated under a NASA contract or grant and considered an important contribution to existing knowledge.
TECHNICAL TRANSLATIONS: Information published in a foreign language considered to merit NASA distribution in English.

SPECIAL PUBLICATIONS: Information derived from or of value to NASA activities. Publications include final reports of major projects, monographs, data compilations, handbooks, sourcebooks, and special bibliographies.

\section{TECHNOLOGY UTILIZATION}

PUBLICATIONS: Information on technology used by NASA that may be of particular interest in commercial and other non-aerospace applications. Publications include Tech Briefs, Technology Utilization Reports and Technology Surveys.

Details on the availability of these publications may be obtained from:

SCIENTIFIC AND TECHNICAL INFORMATION OFFICE

NATIONAL AERONAUTICS AND SPACE ADMINISTRATION

Washington, D.C. 20546 